\title{
1 Reovirus infection is regulated by NPC1 and endosomal
}

2 cholesterol homeostasis

4 Paula Ortega-Gonzalez, ${ }^{1,2,3,4}$ Gwen Taylor, ${ }^{3,4}$ Rohit K. Jangra, ${ }^{5, \dagger}$ Raquel Tenorio, ${ }^{1}$

5 Isabel Fernández de Castro, ${ }^{1}$ Bernardo A. Mainou, $, 6,+\dagger$ Robert C. Orchard, ${ }^{7}$ Craig B.

6 Wilen, ${ }^{8}$ Pamela H. Brigleb, ${ }^{3,9}$ Jorna Sojati, ${ }^{3,9}$ Kartik Chandran, ${ }^{5}$ Cristina Risco,,${ }^{1,}$ and

7 Terence S. Dermody,,$^{3,4,9, *}$

${ }^{1}$ Cell Structure Laboratory, National Center for Biotechnology, CNB-CSIC, campus

UAM, Cantoblanco, 28049 Madrid, Spain

${ }^{2}$ PhD Program in Molecular Biosciences, Autonoma de Madrid University, 28049

Madrid, Spain

${ }^{3}$ Department of Pediatrics, University of Pittsburgh School of Medicine, Pittsburgh,

Pennsylvania, USA

${ }^{4}$ Institute of Infection, Inflammation, and Immunity, UPMC Children's Hospital of

Pittsburgh, Pittsburgh, Pennsylvania, USA

${ }^{5}$ Department of Microbiology and Immunology, Albert Einstein College of Medicine,

${ }^{6}$ Department of Pediatrics, Vanderbilt University School of Medicine, Nashville, 
${ }^{7}$ Department of Immunology, University of Texas Southwestern Medical Center, Dallas,

Texas, USA

${ }^{8}$ Departments of Laboratory Medicine and Immunobiology, Yale University School of

Medicine, New Haven, Connecticut, USA

${ }^{9}$ Department of Microbiology and Molecular Genetics, University of Pittsburgh School of

Medicine, Pittsburgh, Pennsylvania, USA

†Current address: Department of Microbiology and Immunology, Louisiana State

${ }^{+\dagger}$ Current address: Centers for Disease Control and Prevention, Atlanta, Georgia, USA

40

$41 \quad$ *Corresponding authors: crisco@cnb.csic.es and terence.dermody@chp.edu

Running title: Reovirus infection is regulated by NPC1 and endosomal cholesterol

44 homeostasis 


\section{Abstract}

Cholesterol homeostasis is required for the replication of many viruses, including Ebola virus, hepatitis C virus, and human immunodeficiency virus-1. Niemann-Pick C1 (NPC1) is an endosomal-lysosomal membrane protein involved in cholesterol trafficking from late endosomes and lysosomes to the endoplasmic reticulum. We identified NPC1 in CRISPR and RNA interference screens as a putative host factor for infection by mammalian orthoreovirus (reovirus). Following internalization via clathrin-mediated endocytosis, the reovirus outer capsid is proteolytically removed, the endosomal membrane is disrupted, and the viral core is released into the cytoplasm where viral transcription, genome replication, and assembly take place. We found that reovirus infection is significantly impaired in cells lacking NPC1, but infection is restored by treatment of cells with hydroxypropyl- $\beta$-cyclodextrin, which binds and solubilizes cholesterol. Absence of NPC1 did not dampen infection by infectious subvirion particles, which are reovirus disassembly intermediates that bypass the endocytic pathway for infection of target cells. NPC1 is not required for reovirus attachment to the plasma membrane, internalization into cells, or uncoating within endosomes. Instead, NPC1 is required for delivery of transcriptionally active reovirus core particles into the cytoplasm. These findings suggest that cholesterol homeostasis, ensured by NPC1 transport activity, is required for reovirus penetration into the cytoplasm, pointing to a new function for NPC1 and cholesterol homeostasis in viral infection. 


\section{Author summary}

66 Genetic screens are useful strategies to identify host factors required for viral infection.

67 NPC1 was identified in independent CRISPR and RNA interference screens as a

68 putative host factor required for reovirus replication. We discovered that NPC1-

69 mediated cholesterol transport is dispensable for reovirus attachment, internalization,

70 and disassembly but required for penetration of the viral disassembly intermediate from

71 late endosomes into the cytoplasm. These findings pinpoint an essential function for

72 cholesterol in the entry of reovirus and raise the possibility that cholesterol homeostasis

73 regulates the entry of other viruses that penetrate late endosomes to initiate replication. 


\section{INTRODUCTION}

Viral replication is dependent on cellular proteins and pathways for entry, transport, and release of the viral genome to sites of replication in the cell. Viral attachment to host cells occurs by interactions with cell-surface proteins, lipids, and carbohydrate moieties at the plasma membrane and often triggers virus uptake by receptor-mediated endocytosis (1-7). Viruses that traverse through endosomes must escape the endosomal compartment and release their genomes at sites of replication to initiate productive infection. Enveloped viruses generally accomplish endosomal escape using mechanisms involving receptor- or $\mathrm{pH}$-mediated fusion of the viral envelope and endosomal membrane $(6,8-10)$. In contrast, nonenveloped viruses penetrate endosomal membranes by establishing small membrane pores or large membrane disruptions $(9,11-13)$. While both enveloped and nonenveloped viruses depend on conformational changes of viral structural proteins to escape endosomes, mechanisms underlying nonenveloped virus membrane penetration are not well understood (6). Mammalian orthoreoviruses (reoviruses) are nonenveloped icosahedral viruses that infect a broad range of mammalian hosts. Reovirus infections are usually asymptomatic in humans, but these viruses have been implicated in development of celiac disease (14). Reovirus virions include two protein shells, the outer capsid, composed primarily of $\mu 1-\sigma 3$ heterohexamers, and core (15-17). The core contains 10 segments of double-stranded (ds) RNA, which are classified by size into three large (L), three medium (M), and four small (S) segments (17). Following receptor-mediated endocytosis, the reovirus outer capsid undergoes a series of conformational changes and disassembly events required for release of transcriptionally active cores into the cytoplasm $(18,19)$. 
Within late endosomes, acid-dependent cathepsin proteases catalyze proteolysis of the viral outer-capsid protein $\sigma 3$ and cleavage of the membrane-penetration protein $\mu 1$ to $\delta$ and $\varphi$, resulting in formation of metastable intermediates termed infectious subvirion particles (ISVPs) (20-24). Endosomal lipid composition induces ISVPs to undergo additional conformational changes resulting in exposure of hydrophobic domains of $\delta$, release of pore-forming fragment $\mu 1 \mathrm{~N}$, and formation of ISVP*S $(25,26)$. Release of $\mu 1 \mathrm{~N}$ during ISVP-to-ISVP* conversion leads to endosomal penetration and liberation of the viral core into the cytoplasm where infection progresses (27-31). Although some essential viral and host factors required for reovirus penetration of the endosome are known, the process is still not well understood.

In this study, we used CRISPR and RNA interference screens to discover that Niemann Pick C1 (NPC1), an endolysosomal transmembrane protein that mediates cholesterol egress from late endosomes for redistribution to cellular membranes (3234 ), is required for reovirus infection. We found that genetic ablation of NPC1 in human brain microvascular endothelial cells (HBMECs) diminishes reovirus infection by virions but not by ISVPs, suggesting that NPC1 is required for steps that differ between virions and ISVPs. Treatment of NPC1-null HBMECs with hydroxypropyl-beta-cyclodextrin $(H \beta C D)$, a macrocycle that binds and solubilizes cholesterol, restored infectivity by reovirus virions, suggesting that endosomal cholesterol homeostasis contributes to efficient reovirus entry. While NPC1 is not required for viral attachment to the plasma membrane, internalization, or uncoating within endosomes, we found that NPC1 is required for efficient release of reovirus cores from endosomes into the cytoplasm. Together, these findings suggest that cholesterol homeostasis, mediated by NPC1 cholesterol transport activity, is essential for reovirus cell entry and penetration into the cytoplasm. 


\section{RESULTS}

\section{CRISPR/Cas-9 and siRNA screens for host factors required for reovirus infection}

\section{identify NPC1}

To discover host factors required for reovirus infection, we conducted genome-wide CRISPR/Cas-9 and siRNA-based cell-survival screens. The CRISPR/Cas-9 screen was conducted using BV2 mouse microglial cells with the murine Asiago sgRNA library targeting over 20,000 genes. BV2 CRISPR cell libraries were infected with reovirus strains type 1 Lang (T1L) and type 3 Dearing (T3D) and cultured for nine days prior to isolation of genomic DNA (gDNA) from surviving cells and deep sequencing. STARS analysis was conducted to identify enriched CRISPR gRNAs within the surviving cell population (Fig. 1A and Table S1). The siRNA screen was conducted using HeLa S3 cells transfected with the ON-TARGET plus siRNA whole genome library targeting over 18,000 genes (35). Transfected cells were infected with reovirus strain T3SA+ and scored for viability using an ATP-dependent luminescence assay. T3SA+ contains nine genes from T1L and the S1 gene from strain T3C44-MA (36). T3SA+ binds all known reovirus receptors and is cytolytic. Robust $Z$ scores (median absolute deviation) were calculated for each sample (Fig. 1B and Table S2).

Key genes and pathways essential for reovirus replication were defined by comparing the CRISPR/Cas-9 and siRNA screen lists using STRING-db (Fig. 1C). In the CRISPR/Cas-9 screen, four functional pathways defined by Gene Ontology (GO) terms were common to both T1L and T3D, including sialic acid biosynthesis and metabolism (Fig. 1D). Sialic acid is a reovirus attachment factor, and genes involved in sialic acid biosynthesis and metabolism, including Slc35a1, are required for T3SA+ replication in BV2 cells (37). These data provide confidence that the target genes identified in the CRISPR/Cas-9 screen represent biologically significant candidates. We 
also compared KEGG pathways identified in the CRISPR/Cas-9 and siRNA screens to increase the likelihood of significant gene targets. Ribosome and lysosome pathways were the only pathways common to both screens (Fig. 1E). Lysosomal genes include Ctsl, Neu1, and Npc1. Cts/ encodes cathepsin L, which is required for cleavage of the reovirus outer capsid to form ISVPs (22). Neu1 encodes neuraminidase, a lysosomal sialidase that cleaves sialic acid linkages required for reovirus infectivity (38). Npc1 encodes NPC1, a cholesterol transporter that resides in the limiting membrane of endosomes and lysosomes $(33,34)$.

\section{Engineering and characterization of HBMECs with CRISPR-targeted Npc1}

Based on the function of NPC1 in cell entry and replication of other viruses (39) and its identification in both CRISPR and siRNA screens, we evaluated a potential role for NPC1 in reovirus replication. Human brain microvascular endothelial cells (HBMECs) are susceptible to reovirus infection (40) and amenable to CRISPR/Cas- 9 gene editing (41). To facilitate these studies, we used CRISPR/Cas-9 gene editing to engineer a clonal HBMEC cell line lacking the NPC1 gene (KO cells). The NPC1 KO cells were complemented by stable transfection of a functional NPC1 allele (KO+ cells).

The newly engineered NPC1 KO and $\mathrm{KO}+$ cell lines were characterized for NPC1 expression and cholesterol distribution relative to wild-type (WT) HBMECs. Expression of NPC1 in WT, $\mathrm{KO}$, and $\mathrm{KO}+$ cells was tested using immunoblotting. As anticipated, NPC1 expression in KO cells was abrogated relative to WT and $\mathrm{KO}+$ cells (Fig. S1A). There was an observable increase in NPC1 expression in $\mathrm{KO}+$ cells compared with WT cells (Fig. S1B), but the difference was not statistically significant. In the absence of functional NPC1, cholesterol reorganizes from a homogeneous distribution to accumulate in endosomal compartments $(32,33)$. To define the 
distribution of cholesterol in NPC1-null HBMECs, we used fluorescent filipin III to label cholesterol in fixed cells and imaged cholesterol distribution using fluorescence microscopy (Fig. S1C). Cholesterol distribution was homogeneous in WT (Fig. S1C, left) and $\mathrm{KO}+$ cells (Fig. S1C, right). However, cholesterol accumulated around the nucleus in KO cells (Fig. S1C, center) in a pattern consistent with the distribution of endosomes (Fig. S1D), confirming the absence of functional NPC1. Thus, KO cells display the expected phenotype of altered cholesterol distribution when NPC1dependent cholesterol transport is disrupted. Furthermore, complementing NPC1 expression in $\mathrm{KO}$ cells restores the normal distribution of cholesterol, demonstrating that the observed phenotype is specific for NPC1 expression.

\section{Reovirus infection by virions but not by ISVPs is impaired in NPC1 KO cells}

ISVPs prepared by treatment of virions in vitro with intestinal or endosomal proteases bind to reovirus receptors and enter target cells by direct penetration of the plasma membrane and bypass requirements for internalization into the endocytic compartment and acid-dependent proteolysis $(21,22,42)$. To determine whether NPC1 is required for reovirus replication, and further whether NPC1 mediates a step in the infectious cycle that differs between virions and ISVPs, we adsorbed WT, KO, and KO+ cells with reovirus strain T1L M1 P208S virions or ISVPs. Reovirus T1L M1-P208S contains a point mutation in the M1 gene that causes viral factories to have a globular morphology similar to the morphology of factories formed by reovirus T3D (43), which renders infected cells easier to detect. Infected cells were visualized by immunofluorescence (IF) staining for reovirus antigen at $18 \mathrm{~h}$ post-adsorption (Fig. 2). Following adsorption with reovirus virions, the number of infected KO cells was reduced by approximately $50 \%$ relative to infected $\mathrm{WT}$ and $\mathrm{KO}+$ cells (Fig. $2 \mathrm{~A}$ ). A similar reduction in the number 
of infected $\mathrm{KO}$ cells relative to WT and $\mathrm{KO}+$ cells was observed when $\mathrm{WT}, \mathrm{KO}$, and $\mathrm{KO}+$ cells were adsorbed with $\mathrm{T} 1 \mathrm{~L}, \mathrm{~T} 3 \mathrm{D}$, and $\mathrm{T} 3 \mathrm{SA}+$ virions, the reovirus strains used in the CRISPR/Cas9 and siRNA screens (Fig. S2). In contrast, no significant differences in numbers of infected cells were observed following adsorption of WT, KO, and $\mathrm{KO}+$ cells with ISVPs (Fig. 2B). Viral progeny production and release was determined by quantifying viral titers in cell lysates and supernatants at 0,24 , and $48 \mathrm{~h}$ following adsorption of WT, KO, and KO+ cells with virions or ISVPs. Following infection by virions, viral titers in lysates and supernatants of KO cells were 10- to 100-fold less than those in WT and $\mathrm{KO}+$ cells (Fig. 2C and E). In contrast, following infection by ISVPs, viral titers in lysates and supernatants of all three cell types were comparable (Fig. 2D and F). Together, these results suggest that NPC1 is required for reovirus infection and functions at a step in the infectious cycle that differs between virions and ISVPs.

\section{NPC1 is not required for reovirus attachment, internalization, or uncoating}

Reovirus entry can be divided into four main stages: viral binding to cell-surface receptors, viral internalization by endocytosis, proteolytic removal of the viral outer capsid, and penetration of the core from late endosomes into the cytosol (19). We characterized NPC1 KO cells for the capacity to support each step of the reovirus entry pathway to define the function of NPC1 in reovirus infection. To determine whether NPC1 is required for reovirus attachment to target cells, we quantified viral binding using flow cytometry. The quantity of virus bound to the surface of all three cell types was comparable, and no statistically significant differences were observed (Fig. 3A). These data suggest that reovirus attachment to cells is not dependent on expression of NPC1. 
To determine whether NPC1 is required for reovirus to access the endocytic pathway of target cells, WT, KO, and $\mathrm{KO}+$ cells were adsorbed with fluorescentlylabeled reovirus particles and monitored for reovirus uptake using live-cell imaging. We found that the kinetics of reovirus internalization into $\mathrm{WT}, \mathrm{KO}$, and $\mathrm{KO}+$ cells were comparable. High-magnification videos (Videos 1, 2, and 3) along with static images obtained at different intervals (Fig. 3B) demonstrate that attached reovirus particles internalize slowly in the first $\sim 0-10$ min post-adsorption. During this time, reovirus particles remain in the periphery, with a few particles coalescing to form large fluorescent puncta. Convergence of immunofluorescent signals suggests co-transport of multiple viral particles in the same endocytic compartment, similar to that observed during reovirus entry into neurons (44). After $~ 15$ min post-adsorption, we observed rapid recruitment of almost every fluorescent puncta to the perinuclear region.

To more precisely define the movement of reovirus virions during entry, we analyzed the trajectories of individual fluorescent virions in Videos 1, 2, and 3 over 36 min using the Spot detector plugin function from Icy software. Trajectory colors change over time in which each color corresponds to an interval of $\sim 7.5 \mathrm{~min}$ in the time-lapse videos (Videos 4, 5, and 6). Analysis of the time-dependent trajectories confirms observations made in the live-imaging videos. Thus, video-microscopic analysis demonstrates that reovirus virions are internalized rapidly into HBMECs and that virion uptake into the endocytic pathway is not impaired in the absence of NPC1.

Following internalization of reovirus virions, acid-dependent cathepsin proteases in late endosomes catalyze disassembly. During disassembly, proteolytic cleavage of the outermost capsid protein, $\sigma 3$, exposes the membrane-penetration protein, $\mu 1$, which is subsequently cleaved to form a variety of intermediates that lead to penetration of the core particle into the cytoplasm (20-24, 27-30). Cells lacking NPC1 have increased 
endosomal pH and decreased cathepsin activity (45), which could impair reovirus uncoating. To determine whether NPC1 is required for reovirus disassembly, we defined the kinetics of reovirus outer-capsid proteolysis in $\mathrm{WT}, \mathrm{KO}$, and $\mathrm{KO}+$ cells by following the formation of the $\delta$ cleavage fragment of the $\mu 1$ protein. Cells were adsorbed with reovirus virions, and viral proteins in cell lysates were visualized by immunoblotting at $0,1,2$, and $3 \mathrm{~h}$ post-adsorption using a reovirus-specific antiserum. No significant differences in the kinetics of $\mu 1$ proteolysis were observed, with an initial $\delta$ cleavage product detected $2 \mathrm{~h}$ after adsorption in WT, KO, and KO+ cells (Fig. 3C). These data suggest that the cathepsins that catalyze reovirus disassembly are not impaired in NPC1 KO HBMECs. Collectively, these results demonstrate that NPC1 is not required for reovirus receptor binding, internalization, or disassembly.

\section{Escape of reovirus cores from endosomes is impaired in cells lacking NPC1}

To determine whether NPC1 is required for escape of reovirus cores into the cytoplasm following disassembly in the endocytic compartment, we imaged cores in fixed cells by IF. Cells were adsorbed with fluorescently labeled reovirus virions and incubated in the presence of cycloheximide for $8 \mathrm{~h}$ post-adsorption to inhibit synthesis of new viral proteins and thus ensure detection of proteins from infecting viral particles. Cells were stained with a CD-63-specific antibody to label endosomes and an antiserum specific for reovirus cores and imaged using confocal microscopy. Small puncta consistent with reovirus cores were observed in WT and $\mathrm{KO}+$ cells, while in $\mathrm{KO}$ cells, cores appeared to accumulate in larger puncta corresponding to endosomes (Fig. 4A). The distribution of virions, cores, and endosomes was determined to quantify the extent of colocalization. The results demonstrate frequent colocalization of cores and endosomes in $\mathrm{KO}$ cells (Manders coefficient [Mc]: 0.7), while there was much less colocalization 
of cores and endosomes in WT and KO+ cells (Mc: 0.3) (Fig. 4B). Colocalization of virions and cores also was more frequent in $\mathrm{KO}$ cells (Mc: $~ 0.45)$ than in WT (Mc: $\sim 0.15$ ) or $\mathrm{KO}+(\mathrm{Mc}: \sim 0.2)$ cells, whereas colocalization of virions and endosomes was comparable in all cell types (Mc: 0.6). These data suggest that cores escape from endosomes more efficiently in the presence of NPC1.

To complement the imagining experiments, we quantified newly synthesized viral s4 mRNA using RT-qPCR. WT, KO, and KO+ cells were adsorbed with reovirus, RNA was isolated, and s4 transcripts were quantified at $0,6,12$, and $24 \mathrm{~h}$ post-adsorption. We observed a statistically significant increase in total s4 RNA in WT and KO+ cells at 12 and $24 \mathrm{~h}$ post-adsorption relative to KO cells (Fig. 5). Together, these results suggest that NPC1 is required for release of transcriptionally active reovirus cores from endosomes into the cytoplasm.

\section{Cholesterol homeostasis is required for reovirus entry}

We thought it possible that NPC1 could serve as an endosomal receptor for reovirus and interact with one or more viral capsid proteins to enable core delivery into the cytoplasm, analogous to the function of NPC1 in Ebola virus infection $(46,47)$. Alternatively, NPC1 might be required to maintain an endosomal environment with appropriate cholesterol levels to allow cores to penetrate endosomes. To distinguish between these possibilities, we tested whether hydroxypropyl- $\beta$-cyclodextrin $(H \beta C D)$, a cyclic oligosaccharide that triggers cholesterol release from the endo-lysosomal compartment $(48,49)$ and has been used to treat persons with Niemann-Pick disease type $C(50,51)$, for the capacity to overcome the effects of NPC1 deficiency on reovirus infection. To determine whether $\mathrm{H} \beta C D$ treatment redistributes cholesterol from endosomal membranes to a homogeneous distribution in the absence of NPC1, NPC1 
KO HBMECs were treated with $1 \mathrm{mM} \mathrm{H \beta CD}$, a non-toxic concentration (Fig. S3A), or PBS for $48 \mathrm{~h}$ prior to staining for the filipin III complex. Cells displaying cholesterol accumulation were distinguished from those with widely distributed cholesterol by quantifying the mean fluorescence intensity (MFI) of filipin III complex staining. Using this approach, an increase in MFI correlates with an increase in cholesterol accumulation. After $\mathrm{H} \beta C D$ treatment, $\mathrm{KO}$ cells displayed a significant redistribution of cholesterol, reducing its accumulation in endosomes and enhancing its distribution broadly throughout the cell, correlating with a statistically significant decrease in MFI (Fig. S3B,C). These data demonstrate that H in $\mathrm{KO}$ cells, resulting in a cholesterol-distribution phenotype comparable to WT and $\mathrm{KO}+$ cells (Fig. S3C).

Once we observed that $\mathrm{H} \beta C D$ treatment effectively redistributes cholesterol in $\mathrm{KO}$ cells and, thus, functionally complements NPC1 deficiency, we tested whether the reovirus entry defect in KO cells is due to the absence of NPC1 or impaired cholesterol homeostasis. WT, KO, and $\mathrm{KO}+$ cells were pre-treated with $1 \mathrm{mM} \mathrm{H} \beta C D$ or PBS for 24 h, adsorbed with reovirus virions or ISVPs, and scored for reovirus infection by immunostaining. Remarkably, $\mathrm{H} \beta C D$ treatment rescued infection of $\mathrm{KO}$ cells by reovirus virions (Fig. 6) but did not appreciably affect infection of WT or KO+ cells. HßCD treatment also did not affect infection of WT, KO, or KO+ cells by ISVPs. These data demonstrate that endosomal cholesterol homeostasis regulates reovirus entry by enhancing penetration of reovirus core particles into the cytoplasm. 


\section{DISCUSSION}

In this study, we identified NPC1 as a putative host factor required for reovirus infection using genome-wide CRISPR/Cas9 and siRNA-based cell-survival screens. NPC1 is an endolysosomal cholesterol transporter that mediates cholesterol homeostasis (32-34). Disruption of NPC1 results in cholesterol accumulation in late endosomes (Sup. Fig. 2C) and leads to Niemann-Pick disease type C, an autosomal-recessive neurodegenerative disorder (32). Early steps in reovirus infection, including receptor binding, acid-dependent proteolytic disassembly, and ISVP-to-ISVP* conversion have been well characterized (19). However, penetration of endosomal membranes and release of viral cores into the cytoplasm are poorly understood processes. We used CRISPR/Cas9 gene-targeted HBMECs lacking NPC1 expression to study the function of NPC1 in reovirus infection. We discovered that NPC1 is dispensable for viral binding to cell-surface receptors (Fig. 3A), internalization of viral particles (Fig. 3B), and disassembly of the viral outer capsid (Fig. 3C). However, NPC1 is required for efficient penetration of reovirus cores into the cytoplasm (Fig. 4). Treatment with H $\beta C D$ reduces cholesterol accumulation in endosomes (Sup. Fig. 3B and 3C) and restores reovirus infectivity in NPC1 KO cells (Fig. 6). These findings suggest that regulation of cholesterol in endosomal compartments is essential for reovirus entry into host cells. NPC1 is required for the replication of several enveloped viruses. The filoviruses Ebola virus and Marburg virus use NPC1 as an intracellular receptor $(46,47)$. NPC1 also functions in enveloped virus replication by maintaining cholesterol homeostasis. Disruption of cholesterol homeostasis by inhibiting NPC1 prevents entry and replication of dengue virus (52) and African swine fever virus (53) and impairs exosome-dependent release of hepatitis C virus (54). Additionally, NPC1 has been implicated in cell entry of quasi-enveloped forms of hepatitis A virus and hepatitis E virus $(55,56)$. However, 
NPC1 had not been previously appreciated to function in the replication of a nonenveloped virus.

We found that reovirus binding, internalization, and uncoating do not require NPC1, suggesting that NPC1 does not function as an intracellular receptor for reovirus. Instead, we found that cholesterol accumulation in the endocytic pathway diminishes the efficiency of reovirus core release into the cytoplasm. Using confocal microscopy, we visualized and quantified the distribution of fluoresceinated reovirus virions, reovirus cores, and late endosomes in infected cells (Fig. 4). Reovirus cores accumulate in the lumen of late endosomes in $\mathrm{KO}$ cells (Fig. 4A), while virions distribute to endosomes comparably in $\mathrm{WT}, \mathrm{KO}$, and $\mathrm{KO}+$ (Fig. 4B). These findings suggest that cores do not escape from endosomes efficiently in the absence of NPC1. RNA synthesis, which occurs in the cytoplasm following release of cores from late endosomes, also was reduced in $\mathrm{KO}$ cells relative to $\mathrm{WT}$ and $\mathrm{KO}+$ cells (Fig. 5), providing evidence that core escape from endosomes is required for initiation of transcription. It is not apparent how cholesterol accumulation in $\mathrm{KO}$ cells blocks core release from late endosomes.

In Niemann-Pick disease type C, disruption of cholesterol homeostasis causes changes in lipid composition of endosomal membranes $(57,58)$, inverting the ratio of phosphatidyl choline (PC) and phosphatidyl ethanolamine (PE). The change in PC:PE ratio may alter mechanical properties of endosomal membranes by inhibiting intraendosomal membrane dynamics to favor negative curvature $(57,59)$. Membrane composition and dynamics can influence viral entry. Negative membrane curvature induced by addition of PE or the action of interferon-induced transmembrane protein 3 (IFITM3) impairs adenovirus protein VI-mediated membrane disruption (60) and enveloped virus fusion (61), respectively. Although reovirus virions are nonenveloped, entry of reovirus into cells also is inhibited by IFITM3 (62). Many nonenveloped viruses 
use membrane-modifying proteins with the capacity to interact, destabilize, and disrupt membranes to mediate genome release into the cytoplasm $(12,63)$. However, the role of specific lipids in these processes is not well defined.

During reovirus entry, ISVP-to-ISVP* conversion leads to release of myristoylated $\mu 1 \mathrm{~N}$, which interacts with late endosomal membranes to facilitate release of cores into the cytoplasm (20-24). PE and PC concentrations in liposomes influence the efficiency of ISVP-to-ISVP* conversion (25). Therefore, it is possible that changes in membrane fluidity, width, or curvature caused by inversion of endosomal membrane PC:PE ratio in NPC1 KO cells impedes membrane insertion of $\mu 1 \mathrm{~N}$ or formation and expansion of the penetration pore. Additionally, accumulation of cholesterol within the endosomal compartment of NPC1 KO cells could limit recruitment of ISVP*s to membrane-inserted $\mu 1 \mathrm{~N}$ and the subsequent penetration of reovirus cores. Within the Reoviridae family, bluetongue virus (BTV) outer-capsid protein VP5 penetrates late endosomal membranes enriched in phospholipid lysobisphosphatidic acid (LBPA), which is dependent on the anionic charge and membrane fluidic properties of LBPA (64). LBPA-enriched late endosomes also are required for efficient rotavirus entry (65). Our data demonstrating the importance of cholesterol homeostasis in reovirus entry, along with the role of LBPA in BTV and rotavirus entry, suggest that the lipid composition of late endosomes influences nonenveloped virus entry and illuminate a potential new target for antiviral therapy.

Our findings parallel those of a companion study indicating a function for WD repeat-containing protein 81 (WDR81) in reovirus entry (66). WDR81 was identified in a CRISPR/Cas9 cell-survival screen using mouse embryo fibroblasts and found to be required for a step in reovirus entry that follows ISVP formation. WDR81 is required for the maturation of late endosomes by modulating levels of phosphatidylinositol 3- 
phosphate (67). These findings, coupled with our studies of NPC1, suggest that ISVPs formed in an altered endocytic compartment of cells lacking either WDR81 or NPC1 cannot launch replication, whereas ISVPs adsorbed to the surface of such cells can. We think that alterations in cholesterol distribution might govern this difference in ISVP behavior.

Cholesterol accumulation due to NPC1 dysfunction also can lead to alterations in the distribution of host proteins, such as annexin A2 (ANXA2), which was identified in our siRNA screen, and annexin A6 (ANXA6) (68). ANXA2 and ANXA6 are multifunctional proteins involved in endosomal trafficking, segregation of membrane lipids, and membrane curvature regulation through membrane-cytoskeleton rearrangements (69). Disruption of NPC1 leads to increased concentrations of ANXA2 and ANXA6 in late endosomes in response to cholesterol accumulation $(70,71)$. It is possible that cholesterol accumulation in cells lacking NPC1 similarly alters the distribution or function of WDR81. Thus, dysfunction of endosomal proteins in NPC1 $\mathrm{KO}$ cells might alter potential interactions of $\mu 1 \mathrm{~N}$ or the reovirus core with specific lipid microdomains or proteins and inhibit core release.

Genetic screens are useful approaches to identify host factors required for viral replication and provide valuable information about virus-cell interactions $(72,73)$. However, genetic screens frequently yield long lists of potential candidates, many of which are false-positives. To increase the likelihood of identifying host factors required for reovirus replication, we compared gene lists obtained from independent genomewide CRISPR/Cas9 and siRNA-based cell-survival screens. Only 28 genes in the CRISPR/Cas9 screens using strains T1L and T3D were identified in the siRNA screen using strain T3SA+, 19 of which are ribosomal genes (Fig. 1B, C). Of the nine nonribosomal genes, several encode proteins required for reovirus entry, including those 
419 involved in sialic acid biosynthesis and metabolism (Nans and Neu) $(37,38)$ and viral

420 disassembly (Cts) (22).

421 Our findings indicate that NPC1, which was identified in both CRISPR/Cas9 and

422 siRNA screens, is required for efficient release of reovirus cores into the cytoplasm by

423 regulating cholesterol homeostasis. High-resolution studies showing the precise

424 distribution of reovirus virions and cores within endosomes will be required to

425 understand how NPC1 and cholesterol homeostasis regulate core release. These

426 studies will allow us to answer the following new questions: Do cores interact with

427 endosomal membranes in NPC1 KO cells? Does cholesterol impede interactions of

428 cores with membranes? Are other lipids or proteins required for core release? Our

429 ongoing work to answer these questions will clarify the functional elements of the

430 reovirus entry pathway and lead to new approaches to block the entry of viruses that

431 depend on tightly regulated cholesterol distribution in the endocytic pathway. 


\section{MATERIALS AND METHODS}

\section{Cells and viruses}

HBMECs were cultured in growth medium (RPMI 1640 (Gibco) supplemented to contain 10\% fetal bovine serum (FBS; VWR 97068-085), 10\% Nu Serum (Corning), $1 \%$ MEM-vitamins (Corning), 1\% sodium pyruvate (Gibco), 1\% MEM non-essential amino acids (Gibco), 1\% L-glutamine (Gibco), 1\% penicillin/streptomycin (Gibco), and 0.1\% amphotericin B (Sigma) or infection medium (growth medium containing $2 \%$ FBS). BV2 mouse microglial cells were cultured in BV2 maintenance medium (DMEM supplemented to contain $10 \%$ FBS, $1 \%$ penicillin/streptomycin, $1 \%$ sodium pyruvate, and $1 \%$ sodium bicarbonate) or selection medium (maintenance media supplemented with $4 \mu \mathrm{g} / \mathrm{ml}$ blasticidin (Thermo Fisher) and $2.5 \mu \mathrm{g} / \mathrm{ml}$ puromycin (Sigma-Aldrich)). HeLa cells were cultured in Dulbecco modified Eagle medium (Gibco) supplemented to contain 10\% FBS, minimal essential medium nonessential amino acid solution (Gibco), $0.11 \mathrm{mg} / \mathrm{mL}$ of sodium pyruvate (Gibco), and $1 \%$ penicillin/ streptomycin, and $0.1 \%$ amphotericin B (Sigma). Spinner-adapted L929 cells (originally obtained from the Bernard Fields laboratory; ATCC CCL-1) were grown in either suspension or monolayers in Joklik's modified Eagle's minimal essential medium (US Biological; M3867) supplemented to contain 5\% FBS, 2 mM L-glutamine, 100 units/ml penicillin, $100 \mu \mathrm{g} / \mathrm{ml}$ streptomycin, and $0.1 \%$ amphotericin B.

Reovirus strains T1L, T3D, T3SA+, and T1L M1-P208S, were prepared from laboratory stocks by plaque purification followed by 3 to 4 passages in L929 cells. T3SA+ contains nine genes from T1L and the S1 gene from T3C44-MA (36). T1L M1P208S contains a point mutation in the M1 gene that causes viral factories to have a globular morphology similar to the morphology of factories formed by reovirus T3D (43) and can be readily scored for infection. Virions were purified from infected L929 cell 
lysates using cesium chloride gradient centrifugation as described (74). Viral titers were determined by plaque assay using L929 cells (75) and expressed as plaque forming units per $\mathrm{ml}(\mathrm{PFU} / \mathrm{ml})$. Reovirus particle concentration was estimated by spectral absorbance of purified virions at $260 \mathrm{~nm}$ (optical density at $260 \mathrm{~nm}\left[\mathrm{OD}_{260}\right]$ of $1=$ $2.1 \times 10^{12}$ particles $\left./ \mathrm{ml}\right)(76)$.

Fluorescent reovirus particles were prepared by diluting $6 \times 10^{12}$ reovirus particles/ml in $50 \mathrm{mM}$ sodium bicarbonate buffer and incubating with $20 \mu \mathrm{M}$ Alexa Fluor $^{\text {TM }} 647$ NHS Ester (Succinimidyl Ester) (Invitrogen, A37573) at room temperature (RT) for $90 \mathrm{~min}$, protected from light (77). Labeled virions were dialyzed at $4^{\circ} \mathrm{C}$ overnight with 2-3 buffer exchanges to remove unreacted dye.

ISVPs were prepared by incubating $2 \times 10^{12}$ purified reovirus particles with 200 $\mu \mathrm{g} / \mathrm{mL}$ chymotrypsin (Sigma, C3142) at $37^{\circ} \mathrm{C}$ for $60 \mathrm{~min}$ (23). Digestion was terminated by the addition of PMSF to a final concentration of $2 \mathrm{mM}$. Virion-to-ISVP conversion was confirmed by SDS-PAGE and colloidal blue staining to assess the loss of $\sigma 3$ and cleavage of $\mu 1 \mathrm{C}$ to $\delta$.

\section{Antibodies and dyes}

Primary antibodies used for indirect immunofluorescence include anti-CD63 (1:250) (Thermofisher, \#10628D), reovirus-specific polyclonal rabbit antiserum (1:1000) (78), and T1L core-specific rabbit antiserum (1:250) provided by Max Nibert (79). Alexa Fluor conjugated secondary antibodies (Thermo Fisher, \#A11034, \#A11030) were used to visualize antigen. Nuclei were stained with 4',6-diamidino-2-phenylindole (DAPI, Invitrogen, D3571). Primary antibodies used for immunoblotting include reovirusspecific polyclonal rabbit antiserum, NPC1-specific polyclonal rabbit antiserum (Abcam, 134113), and mouse GAPDH monoclonal antibody for protein loading controls (Sigma, 
482

483

484

485

486

487

488

489

490

491

492

493

494

495

496

497

498

499

500

501

502

503

504

505

G8795). Anti-mouse IRDye680RD and anti-rabbit IRDye800CW (Licor) secondary antibodies were used.

\section{CRISPR Screen}

The screen was conducted and transduction validated as described (80). BV2 cells were transduced with pXPR_101 lentivirus encoding Cas9 (Addgene; 52962) and propagated for 11 days with BV2 Maintenance Medium supplemented to contain blasticidin. These parental BV2 or BV2-Cas9 cells were transduced for 2 days with pXPR_011 expressing eGFP (Addgene; 59702) and a short guide RNA (sgRNA) targeting eGFP at a multiplicity of infection (MOI) of less than $1 \mathrm{PFU} /$ cell. Cells were selected for 5 days with BV2 selection medium. The frequency of eGFP-expressing cells was quantified by flow cytometry.

The murine Asiago sgRNA CRISPR library contains six independent genomewide pools, in which each pool contains unique sgRNAs targeting 20,077 mouse genes. Four pools of the Asiago library were transduced into $5 \times 10^{7} \mathrm{BV} 2$ cells at an $\mathrm{MOI}$ of 0.2 PFU/cell to establish four BV2 libraries. Two days post-transduction, cells were transferred to BV2 Selection Medium and propagated for 5 additional days. For each experimental condition, $10^{7}$ BV2 library cells expressing Cas9 and sgRNAs were seeded in duplicate into T175 tissue culture flasks (Greiner Bio-One). Cells were inoculated with Opti-MEM supplemented to contain PBS (mock) or reovirus strains T1L or T3D at an $\mathrm{MOI}$ of $100 \mathrm{PFU} /$ cell. Cells were incubated at RT for $1 \mathrm{~h}$, followed by the addition of $20 \mathrm{~mL}$ of DMEM supplemented to contain $10 \% \mathrm{FBS}, 1 \%$ penicillin/streptomycin, 1\% sodium pyruvate, and 1\% sodium bicarbonate. After 2 days post-inoculation (dpi) (mock) or $9 \mathrm{dpi}$ (T1L or T3D conditions), cells were harvested and 
506

507

508

genomic DNA (gDNA) was isolated from surviving cells using a QIAmp DNA Mini Kit (QIAGEN) according to the manufacturer's instructions.

\section{CRISPR screen sequencing and analysis}

Illumina sequencing and STARS analyses were conducted as described (81). The gDNA was aliquoted into a 96-well plate (Greiner Bio-One) with up to $10 \mu \mathrm{g}$ gDNA in 50 $\mu \mathrm{L}$ of total volume per well. A polymerase chain reaction (PCR) master mix containing ExTaq DNA polymerase (Clontech), ExTaq buffer (Clontech), dNTPs, P5 stagger primer, and water was prepared. PCR master mix $(40 \mu \mathrm{L})$ and $10 \mu \mathrm{L}$ of a barcoded primer were added to each well containing gDNA. Samples were amplified using the following protocol: $95^{\circ} \mathrm{C}$ for $1 \mathrm{~min}$, followed by 28 cycles of $94^{\circ} \mathrm{C}$ for $50 \mathrm{~s}, 52.5^{\circ} \mathrm{C}$ for 30 $\mathrm{s}$, and $72^{\circ} \mathrm{C}$ for $30 \mathrm{~s}$, and ending with a final $72^{\circ} \mathrm{C}$ extension for $10 \mathrm{~min}$. PCR product was purified using Agencourt AMPure XP SPRI beads (Beckman Coulter) according to the manufacturer's instructions. Samples were sequenced using a HiSeq 2000 (Illumina). Following deconvolution of the barcodes in the P7 primer, sgRNA sequences were mapped to a reference file of sgRNAs from the Asiago library. To account for the varying number of reads per condition, read counts per sgRNA were normalized to $10^{7}$ total reads per sample. Normalized values were then log-2 transformed. sgRNAs that were not detected were arbitrarily assigned a read count of 1 . sgRNA frequencies were analyzed using STARS software to produce a rank ordered score for each gene. This score correlated with the sgRNA candidates that were above $10 \%$ of the total sequenced sgRNAs. Genes scoring above this threshold in either of the two independent subpools and in at least two of the four independent genome-wide pools were assigned a STAR score. In addition to the STAR score, screen results were 
compared using false discovery rate (FDR) analyses to monitor gene-specific signal versus background noise. Statistical values of independent replicates were averaged.

\section{Whole genome siRNA screen and analysis}

The whole genome siRNA screen was conducted as described (35) using HeLa S3 cells and the Dharmacon ON-TARGETplus ${ }^{\circledR}$ SMARTpool® human siRNA library (Thermo Scientific) and strain T3SA+.

\section{Production of NPC1 KO and KO+ cell lines}

HBMEC single-cell clones with ablation of the NPC1 gene were engineered using CRISPR/Cas9-mediated gene editing as described (82) using an NPC1-specific gRNA (5' GGCCTTGTCATTACTTGAGGGGG 3', targeting nucleotides 768-790 of the human NPC1 mRNA). Single-cell clones were screened for the loss of NPC1 function by filipin III staining (82). Genotype of the selected NPC1 KO clones was confirmed by Sanger sequencing followed by amplification of the genomic DNA sequences flanking the gRNA target site using forward (5' TCATAAACACACCAAACTTGGAATC 3') and reverse (5' TCCTGCGGCAGAGGTTTTC 3') primers. Sequences of the NPC1 alleles were deconvoluted using CRISP-ID (83). To confirm the specificity of Npc1 knockout, cells of a single clone were transduced with a retrovirus vector (pBabe-Puro) expressing human NPC1 as described (47).

\section{Indirect immunofluorescence staining}

Cells were fixed with 4\% paraformaldehyde (PFA, Electron Microscopy Sciences, 15712-s) in $\mathrm{PBS}^{-/}$at RT for 20 min, washed three times with $\mathrm{PBS}^{-/}$, and permeabilized and blocked with $0.1 \%$ Triton X-100 and $2 \% \mathrm{FBS}^{\text {in } \mathrm{PBS}^{-/}}$at RT for 20 min. Cells were 
555

incubated sequentially with primary antibody, Alexa Fluor-conjugated secondary antibody, and DAPI diluted in PBS $^{-1-}$ containing $0.1 \%$ Triton X-100 and $2 \%$ FBS at RT for 30 to $60 \mathrm{~min}$. For cholesterol labeling, fixed and permeabilized cells were incubated with $50 \mu \mathrm{g} / \mathrm{ml}$ filipin III (Sigma, SAE0088) diluted in PBS ${ }^{-/-}$for 30 min. Coverslips were mounted using Prolong-gold (Molecular Probes). Confocal images were captured using a Leica-SP8 laser scanning confocal microscope equipped with an HCX PL APO 63X/1.4 N.A oil objective and processed using Fiji/lmageJ software.

\section{SDS-PAGE and Immunoblotting}

Cells harvested for protein extraction were lysed in Radioimmunoprecipitation Assay buffer (RIPA buffer; Thermo Fisher) supplemented with 1X protease inhibitors (Thermo Fisher). Protein concentration was quantified by Bradford assay (Bio-Rad) following the manufacturer's protocol. Samples for SDS-PAGE were diluted in 5X Laemmli sample buffer (Bio-Rad) containing 10\% $\beta$-mercaptoethanol and incubated at $95^{\circ} \mathrm{C}$ for $10 \mathrm{~min}$. Samples for detection of NPC1 were incubated at $70^{\circ} \mathrm{C}$ for $10 \mathrm{~min}$ to prevent aggregation. Equal amounts of protein were electrophoresed in $10 \%$ or $4-20 \%$ MiniProtean TGX gels (Bio-Rad). Following electrophoresis, proteins were transferred to nitrocellulose membranes (Bio-Rad) for immunoblotting. Nitrocellulose membranes were incubated with $5 \%$ nonfat milk in TBS $(50 \mathrm{mM}$ Tris- $\mathrm{HCl}, \mathrm{pH} 7.6 ; 150 \mathrm{mM} \mathrm{NaCl})$ with $0.1 \%$ Tween 20 (TBS-T) and sequentially incubated with primary and secondary antibodies diluted in TBS-T at RT for $1 \mathrm{~h}$. Immunoblot images were captured using an Odyssey CLx imaging system (Li-Cor) and protein bands were quantified using the Image Studio Lite software. Protein expression levels were normalized to GAPDH loading controls. 


\section{Quantification of reovirus infectivity}

In experiments comparing infectivity of reovirus in $\mathrm{KO}, \mathrm{KO}+$, and WT HBMECs, cells were adsorbed with 10,000 reovirus virions or 100 ISVPs diluted in Opti-MEM (Invitrogen) at $37^{\circ} \mathrm{C}$ for $1 \mathrm{~h}$. Following adsorption, the inoculum was removed, and cells were incubated in infection medium for $18 \mathrm{~h}$ before fixing in ice-cold methanol. In experiments comparing reovirus infectivity in the presence or absence of $H \beta C D$, cells were treated with $1 \mathrm{mM} \mathrm{H} \beta C D$ or PBS for $24 \mathrm{~h}$ prior to adsorption with reovirus. Following adsorption, fresh $1 \mathrm{mM} \mathrm{H} \beta C D$ was added to the medium for $18 \mathrm{~h}$ before fixing in ice-cold methanol. Fixed cells were washed with $\mathrm{PBS}^{-1-}$, blocked with $1 \%$ bovine serum albumin (BSA), and incubated sequentially with reovirus-specific polyclonal rabbit antiserum, Alexa Fluor 488-conjugated anti-rabbit antibody, and DAPI in PBS ${ }^{-1-}$ containing $0.5 \%$ Triton X-100. Cells were imaged using a Lionheart FX automated imager (BioTek) equipped with a 20X air objective, taking four fields-of-view from duplicate samples. Images were processed and signals quantified using Gen5+ software (BioTek).

\section{Viral binding}

$\mathrm{KO}, \mathrm{KO}+$, and WT HBMECs were detached from tissue-culture plates using

CellStripper dissociation reagent (Corning), quenched with HBMEC medium, and washed with $\mathrm{PBS}^{--}$. Cells were resuspended in $\mathrm{PBS}^{---}$at $10^{6} \mathrm{cells} / \mathrm{ml}$ and adsorbed with 10,000 Alexa Fluor 647 -labeled reovirus virions $/$ cell at $4^{\circ} \mathrm{C}$ for $1 \mathrm{~h}$ with agitation. After binding, cells were washed twice with $\mathrm{PBS}^{-/-}$and fixed with 1\% paraformaldehyde (PFA) supplemented with propidium iodide to determine cell viability. Cells were analyzed using an LSRII flow cytometer (BD Bioscience). Results were quantified using FlowJo V10 software. 


\section{Live microscopy of reovirus internalization}

607

$\mathrm{KO}, \mathrm{KO}+$, and $\mathrm{WT} \mathrm{HBMEC}$ were plated on glass-bottom $\mathrm{p} 35$ plates and adsorbed with 10,000 Alexa 647 -labeled reovirus virions $/$ cell at $4^{\circ} \mathrm{C}$ for $45 \mathrm{~min}$ to synchronize infection. The inoculum was removed and replaced with fresh Opti-MEM without phenol-red medium supplemented with $2 \%$ FBS. Reovirus transport was imaged using a Leica DMI6000B fluorescence microscope with an HCX PL APO 63X/1.30 Gly objective. Fluorescence and brightfield images were collected from 0 to $36 \mathrm{~min}$ post adsorption every $\sim 25 \mathrm{sec}$.

\section{Tracking of reovirus transport}

Automated tracking of fluorescent reovirus particles in time-lapse images was conducted using Icy bioimage analysis software. Regions of interest (ROI) corresponding to the cell periphery were selected for tracking analysis using the Spot Detector plugin (84). The scale of the object (reovirus virions) to be analyzed was set at a size of $\sim 7$ pixels per spot, and the threshold sensitivity was set at 100 . Parameters describing transport dynamics were considered as both diffusive and directed for running tracking analysis. Results are presented in colored time-dependent tracks.

\section{Quantification of reovirus cores}

$\mathrm{KO}, \mathrm{KO}+$, and WT HBMECs were adsorbed with 10,000 Alexa Fluor 647-labeled reovirus virions at $37^{\circ} \mathrm{C}$ for $45 \mathrm{~min}$. The inoculum was removed, and the cells were incubated in infection medium containing $100 \mu \mathrm{g} / \mathrm{ml}$ of cycloheximide for $8 \mathrm{~h}$. After fixation, cells were permeabilized and stained with $\mathrm{T} 1 \mathrm{~L}$ core-specific rabbit polyclonal serum and anti-CD63 antibody. Confocal images were captured using a Leica-SP8 
630

631

635

636

637

638

639

640

641

642

643

644

645

646

647

648

649

650

651

652

laser scanning confocal microscope equipped with an HCX PL APO 63X/1.4 N.A oil

objective and processed using Fiji/lmageJ software. Colocalization of fluorescent

reovirus virions (cyan puncta), reovirus cores (green puncta), and late endosomes (red

puncta) was analyzed to differentiate infecting virions from cores released into the cytoplasm.

\section{RNA extraction and purification}

Cells were lysed using TRIzol reagent (Invitrogen). RNA was extracted with chloroform and purified using a PureLink RNA minikit (Invitrogen) with DNase treatment according to the manufacturer's instructions.

\section{S4 quantitative RT-PCR}

Total S4 RNA was quantified using qScript XLT one-step RT-qPCR ToughMix, Low ROX (Quanta Bioscience) and T3D_S4_qPCR primers (Forward:

GAAGCATTTGCCTCACCATAG, Reverse: GATCTGTCCAACTTGAGTGTATTG) according to the manufacturer's instructions. The following RT-qPCR cycling protocol was used: cDNA synthesis $\left(50^{\circ} \mathrm{C}\right.$ for $\left.10 \mathrm{~min}\right)$, initial denaturation $\left(95^{\circ} \mathrm{C}\right.$ for $\left.1 \mathrm{~min}\right)$, and 40 PCR cycles $\left(95^{\circ} \mathrm{C}\right.$ for $10 \mathrm{~s}$ followed by a data collection step at $60^{\circ} \mathrm{C}$ for $\left.1 \mathrm{~min}\right) . \mathrm{S} 4$ cDNA was detected using a fluorogenic probe (5'-FAM [fluorescent fluorescein]AGCGCGCAAGAGGGATGGGA-BHQ [black hole quencher]-1-3'; Biosearch Technologies).

\section{Statistical analysis}


bioRxiv preprint doi: $h$ ttps://doi.org/10.1101/2021.09.27.462002; this version posted September 30, 2021. The copyright holder for this preprint (which was not certified by peer review) is the author/funder, who has granted bioRxiv a license to display the preprint in perpetuity. It is made available under aCC-BY-NC-ND 4.0 International license.

653 All data were analyzed using Graphpad Prism 8. Figure legends specify the number of 654 experimental repeats and the statistical test applied for each analysis. Differences were 655 considered statistically significant when $P$ values were less than 0.05 . 


\section{Acknowledgements}

We thank members of the Dermody and Risco laboratories for many useful discussions and Dr. Pranav Danthi for review of the manuscript and sharing data from his laboratory prior to publication. We thank Dr. Martin Sachse for expert advice and review of the manuscript and Drs. Sylvia Gutiérrez-Erlandsson and Ana Oña for assistance with confocal microscopy. We are grateful to the UPMC Children's Hospital of Pittsburgh Rangos Research Center Cell Imaging Core Laboratory for assistance with microscopy. This work was supported in part by Public Health Service award R01 AI032539 (C.R. and T.S.D.) and the Heinz Endowments (T.S.D.) and grants BIO2015-68758-R and RTI2018-094445-B-100 from the Ministry of Science and Innovation of Spain (C.R.).

\section{Competing interests}

The authors have declared that no competing interests exist.

\section{Author contributions}

Conceived and designed experiments: POG, GT, CR, and TSD. Conducted experiments: POG, GT, RKJ, BAM, RCO, and CBW. Analyzed data: POG and GT. Contributed reagents/materials/analysis tools: $\mathrm{RKJ}, \mathrm{RCO}, \mathrm{CBW}$, and KC. Wrote original draft: POG, GT, and TSD. Reviewed and edited paper: POG, GT, RKJ, RT, IF, BAM, RCO, CBW, PAB, JS, KC, CR, and TSD. 


\section{REFERENCES}

1. Mercer J, Helenius A. Virus entry by macropinocytosis. Nat Cell Biol. 2009;11(5):510-20.

2. Mercer J, Schelhaas M, Helenius A. Virus entry by endocytosis. Annu Rev Biochem. 2010;79:803-33.

3. Yamauchi Y, Helenius A. Virus entry at a glance. J Cell Sci. 2013;126(Pt 6):1289-95.

4. Smith $A E$, Helenius A. How viruses enter animal cells. Science. 2004;304(5668):237-42.

5. Tsai B. Penetration of nonenveloped viruses into the cytoplasm. Annu Rev Cell Develop Biol. 2007;23:23-43.

6. Staring J, Raaben M, Brummelkamp TR. Viral escape from endosomes and host detection at a glance. J Cell Sci. 2018;131(15).

7. Harrison SC. Viral membrane fusion. Virology. 2015;479-480:498-507.

8. White JM, Whittaker GR. Fusion of enveloped viruses in endosomes. Traffic. 2016;17(6):593-614.

9. Sieczkarski SB, Whittaker GR. Viral entry. Curr Top Microbiol Immunol. 2005;285:1-23.

10. Plemper RK. Cell entry of enveloped viruses. Curr Opin Virol. 2011;1(2):92-100.

11. Stewart PL, Dermody TS, Nemerow GR. Structural basis of nonenveloped virus cell entry. Adv Protein Chem. 2003;64:455-91.

12. Kumar CS, Dey D, Ghosh S, Banerjee M. Breach: Host membrane penetration and entry by nonenveloped viruses. Trends Microbiol. 2018;26(6):525-37.

13. Banerjee M, Johnson JE. Activation, exposure and penetration of virally encoded, membrane-active polypeptides during non-enveloped virus entry. Curr Protein Pept Sci. 2008;9(1):16-27.

14. Bouziat R, Hinterleitner R, Brown JJ, Stencel-Baerenwald JE, Ikizler M, Mayassi $\mathrm{T}$, et al. Reovirus infection triggers inflammatory responses to dietary antigens and development of celiac disease. Science. 2017;356(6333):44-50.

15. Dryden KA, Wang G, Yeager M, Nibert ML, Coombs KM, Furlong DB, et al. Early steps in reovirus infection are associated with dramatic changes in supramolecular structure and protein conformation: analysis of virions and subviral particles by cryoelectron microscopy and image reconstruction. J Cell Biol. 1993;122(5):1023-41.

16. Zhang X, Ji Y, Zhang L, Harrison SC, Marinescu DC, Nibert ML, et al. Features of reovirus outer capsid protein $\mathrm{m} 1$ revealed by electron cryomicroscopy and image reconstruction of the virion at $7.0 \AA$ resolution. Structure. 2005;13(10):1545-57. 
17. Dermody TS, Parker JS, Sherry B. Orthoreoviruses. In: Knipe DM, Howley PM, editors. Fields Virology. 2. 6th ed. Philadelphia: Lippincott Williams \& Wilkins; 2013. p. 1304-46.

18. Gummersheimer SL, Snyder AJ, Danthi P. Control of capsid transformations during reovirus entry. Viruses. 2021;13(2):153.

19. Roth AN, Aravamudhan P, Fernández de Castro I, Tenorio R, Risco C, Dermody TS. Ins and outs of reovirus: vesicular trafficking in viral entry and egress. Trends Microbiol. 2021;29(4):363-75.

20. Borsa J, Sargent MD, Lievaart PA, Copps TP. Reovirus: evidence for a second step in the intracellular uncoating and transcriptase activation process. Virology. 1981;111(1):191-200.

21. Sturzenbecker LJ, Nibert ML, Furlong DB, Fields BN. Intracellular digestion of reovirus particles requires a low $\mathrm{pH}$ and is an essential step in the viral infectious cycle. J Virol 1987;61(8):2351-61.

22. Ebert DH, Deussing J, Peters C, Dermody TS. Cathepsin L and cathepsin B mediate reovirus disassembly in murine fibroblast cells. J Biol Chem. 2002;277(27):24609-17.

23. Baer GS, Dermody TS. Mutations in reovirus outer-capsid protein s3 selected during persistent infections of $L$ cells confer resistance to protease inhibitor E64. J Virol. 1997;71:4921-8.

24. Silverstein SC, Astell C, Levin DH, Schonberg M, Acs G. The mechanism of reovirus uncoating and gene activation in vivo. Virology. 1972;47(3):797-806.

25. Snyder AJ, Danthi P. Lipid membranes facilitate conformational changes required for reovirus cell entry. J Virol. 2015;90(5):2628-38.

26. Snyder AJ, Danthi P. Lipids cooperate with the reovirus membrane penetration peptide to facilitate particle uncoating. J Biol Chem. 2016;291(52):26773-85.

27. Odegard AL, Chandran K, Zhang X, Parker JS, Baker TS, Nibert ML. Putative autocleavage of outer capsid protein $\mathrm{m} 1$, allowing release of myristoylated peptide $\mathrm{m} 1 \mathrm{~N}$ during particle uncoating, is critical for cell entry by reovirus. J Virol. 2004;78(16):873245.

28. Agosto MA, Ivanovic T, Nibert ML. Mammalian reovirus, a nonfusogenic nonenveloped virus, forms size-selective pores in a model membrane. Proc Natl Acad Sci U S A. 2006;103(44):16496-501.

29. Ivanovic T, Agosto MA, Zhang L, Chandran K, Harrison SC, Nibert ML. Peptides released from reovirus outer capsid form membrane pores that recruit virus particles. EMBO J. 2008;27(8):1289-98.

30. Chandran K, Farsetta DL, Nibert ML. Strategy for nonenveloped virus entry: a hydrophobic conformer of the reovirus membrane penetration protein $\mathrm{m} 1$ mediates membrane disruption. J Virol. 2002;76(19):9920-33. 
31. Zhang L, Agosto MA, Ivanovic T, King DS, Nibert ML, Harrison SC. Requirements for the formation of membrane pores by the reovirus myristoylated micro1N peptide. J Virol. 2009;83(14):7004-14.

32. Carstea ED, Morris JA, Coleman KG, Loftus SK, Zhang D, Cummings C, et al. Niemann-Pick $\mathrm{C} 1$ disease gene: homology to mediators of cholesterol homeostasis. Science. 1997;277(5323):228-31.

33. Ioannou YA. The structure and function of the Niemann-Pick C1 protein. Mol Genet Metab. 2000;71(1-2):175-81.

34. Kwon HJ, Abi-Mosleh L, Wang ML, Deisenhofer J, Goldstein JL, Brown MS, et al. Structure of N-terminal domain of NPC1 reveals distinct subdomains for binding and transfer of cholesterol. Cell. 2009;137(7):1213-24.

35. Konopka-Anstadt JL, Mainou BA, Sutherland DM, Sekine Y, Strittmatter SM, Dermody TS. The Nogo receptor NgR1 mediates infection by mammalian reovirus. Cell Host Microbe. 2014;15(6):681-91.

36. Barton ES, Connolly JL, Forrest JC, Chappell JD, Dermody TS. Utilization of sialic acid as a coreceptor enhances reovirus attachment by multistep adhesion strengthening. J Biol Chem. 2001;276(3):2200-11.

37. Urbanek K, Sutherland DM, Orchard RC, Wilen CB, Knowlton JJ, Aravamudhan $\mathrm{P}$, et al. Cytidine monophosphate $\mathrm{N}$-acetylneuraminic acid synthetase and solute carrier family 35 member A1 are required for reovirus binding and infection. J Virol. 2020;95(2).

38. Gentsch JR, Pacitti AF. Effect of neuraminidase treatment of cells and effect of soluble glycoproteins on type 3 reovirus attachment to murine L cells. J Virol. 1985;56(2):356-64.

39. Avula K, Singh B, Kumar PV, Syed GH. Role of lipid transfer proteins (LTPs) in the viral life cycle. Front Microbiol. 2021;12:673509.

40. Lai CM, Mainou BA, Kim KS, Dermody TS. Directional release of reovirus from the apical surface of polarized endothelial cells. mBio. 2013;4(2):e00049-13.

41. Fu J, Li L, Huo D, Zhi S, Yang R, Yang B, et al. Astrocyte-derived TGF $\beta 1$ facilitates blood-brain barrier function via non-canonical hedgehog signaling in brain microvascular endothelial cells. Brain Sci. 2021;11(1).

42. Borsa J, Copps TP, Sargent MD, Long DG, Chapman JD. New intermediate subviral particles in the in vitro uncoating of reovirus virions by chymotrypsin. J Virol. 1973;11(4):552-64.

43. Parker JS, Broering TJ, Kim J, Higgins DE, Nibert ML. Reovirus core protein m2 determines the filamentous morphology of viral inclusion bodies by interacting with and stabilizing microtubules. J Virol. 2002;76(9):4483-96.

44. Aravamudhan P, Raghunathan K, Konopka-Anstadt J, Pathak A, Sutherland DM, Carter BD, et al. Reovirus uses macropinocytosis-mediated entry and fast axonal transport to infect neurons. PLoS Pathog. 2020;16(2):e1008380. 
45. Elrick MJ, Yu T, Chung C, Lieberman AP. Impaired proteolysis underlies autophagic dysfunction in Niemann-Pick type $\mathrm{C}$ disease. Hum Mol Genet. 2012;21(22):4876-87.

46. Carette JE, Raaben M, Wong AC, Herbert AS, Obernosterer G, Mulherkar N, et al. Ebola virus entry requires the cholesterol transporter Niemann-Pick C1. Nature. 2011;477(7364):340-3.

47. Miller EH, Obernosterer G, Raaben M, Herbert AS, Deffieu MS, Krishnan A, et al. Ebola virus entry requires the host-programmed recognition of an intracellular receptor. EMBO J. 2012;31(8):1947-60.

48. Rosenbaum Al, Zhang G, Warren JD, Maxfield FR. Endocytosis of betacyclodextrins is responsible for cholesterol reduction in Niemann-Pick type $\mathrm{C}$ mutant cells. Proc Natl Acad Sci U S A. 2010;107(12):5477-82.

49. Peake KB, Vance JE. Normalization of cholesterol homeostasis by 2hydroxypropyl- $\beta$-cyclodextrin in neurons and glia from Niemann-Pick C1 (NPC1)deficient mice. J Biol Chem. 2012;287(12):9290-8.

50. Liu B, Turley SD, Burns DK, Miller AM, Repa JJ, Dietschy JM. Reversal of defective lysosomal transport in NPC disease ameliorates liver dysfunction and neurodegeneration in the npc1-/- mouse. Proc Natl Acad Sci U S A. 2009;106(7):237782.

51. Ory DS, Ottinger EA, Farhat NY, King KA, Jiang X, Weissfeld L, et al. Intrathecal 2-hydroxypropyl- $\beta$-cyclodextrin decreases neurological disease progression in Niemann-Pick disease, type C1: a non-randomised, open-label, phase 1-2 trial. Lancet. 2017;390(10104):1758-68.

52. Poh MK, Shui G, Xie X, Shi PY, Wenk MR, Gu F. U18666A, an intra-cellular cholesterol transport inhibitor, inhibits dengue virus entry and replication. Antiviral Res. 2012;93(1):191-8.

53. Cuesta-Geijo M, Chiappi M, Galindo I, Barrado-Gil L, Muñoz-Moreno R, Carrascosa JL, et al. Cholesterol flux is required for endosomal progression of African swine fever virions during the initial establishment of infection. J Virol. 2016;90(3):153443.

54. Elgner F, Ren H, Medvedev R, Ploen D, Himmelsbach K, Boller K, et al. The intracellular cholesterol transport inhibitor U18666A inhibits the exosome-dependent release of mature hepatitis C virus. J Virol. 2016;90(24):11181-96.

55. Yin X, Ambardekar C, Lu Y, Feng Z. Distinct entry mechanisms for nonenveloped and quasi-enveloped hepatitis E viruses. J Virol. 2016;90(8):4232-42.

56. Rivera-Serrano EE, González-López O, Das A, Lemon SM. Cellular entry and uncoating of naked and quasi-enveloped human hepatoviruses. eLife. 2019;8.

57. Sobo K, Le Blanc I, Luyet PP, Fivaz M, Ferguson C, Parton RG, et al. Late endosomal cholesterol accumulation leads to impaired intra-endosomal trafficking. PloS one. $2007 ; 2(9): e 851$.

\section{Vanier MT. Niemann-Pick disease type C. Orphanet J Rare Dis. 2010;5:16.}


59. Koller D, Lohner K. The role of spontaneous lipid curvature in the interaction of interfacially active peptides with membranes. Biochim Biophys Acta. 2014;1838(9):2250-9.

60. Maier O, Galan DL, Wodrich H, Wiethoff CM. An N-terminal domain of adenovirus protein VI fragments membranes by inducing positive membrane curvature. Virology. 2010;402(1):11-9.

61. Guo X, Steinkühler J, Marin M, Li X, Lu W, Dimova R, et al. Interferon-induced transmembrane protein 3 blocks fusion of diverse enveloped viruses by altering mechanical properties of cell membranes. ACS Nano. 2021;15(5):8155-70.

62. Anafu AA, Bowen $\mathrm{CH}$, Chin $\mathrm{CR}$, Brass AL, Holm GH. Interferon-inducible transmembrane protein 3 (IFITM3) restricts reovirus cell entry. J Biol Chem. 2013;288(24):17261-71.

63. Moyer CL, Wiethoff CM, Maier O, Smith JG, Nemerow GR. Functional genetic and biophysical analyses of membrane disruption by human adenovirus. J Virol. 2011;85(6):2631-41.

64. Patel A, Mohl BP, Roy P. Entry of Bluetongue virus capsid requires the late endosome-specific lipid lysobisphosphatidic acid. J Biol Chem. 2016;291(23):12408-19.

65. Silva-Ayala D, López T, Gutiérrez M, Perrimon N, López S, Arias CF. Genomewide RNAi screen reveals a role for the ESCRT complex in rotavirus cell entry. Proc Natl Acad Sci U S A. 2013;110(25):10270-5.

66. Snyder A, Abad A, Danthi, P. A CRISPR-Cas9 screen reveals a role for WD repeat-containing protein (WDR81) in the entry of late penetrating viruses. bioRxiv preprint, doi:https://biorxiv.org/cgi/content/short/2021.09.26.461887v1, 2021.

67. Liu K, Jian Y, Sun X, Yang C, Gao Z, Zhang Z, et al. Negative regulation of phosphatidylinositol 3-phosphate levels in early-to-late endosome conversion. J Cell Biol. 2016;212(2):181-98.

68. Wheeler S, Schmid R, Sillence DJ. Lipid-protein interactions in Niemann-Pick type C Disease: Insights from molecular modeling. Int J Mol Sci. 2019;20(3).

69. Rentero C, Blanco-Munoz P, Meneses-Salas E, Grewal T, Enrich C. Annexinscoordinators of cholesterol homeostasis in endocytic pathways. Int $\mathrm{J}$ Mol Sci. 2018;19(5):E1444.

70. de Diego I, Schwartz F, Siegfried H, Dauterstedt P, Heeren J, Beisiegel U, et al. Cholesterol modulates the membrane binding and intracellular distribution of annexin 6 . J Biol Chem. 2002;277(35):32187-94.

71. Mayran N, Parton RG, Gruenberg J. Annexin II regulates multivesicular endosome biogenesis in the degradation pathway of animal cells. EMBO J. 2003;22(13):3242-53.

72. Hirsch AJ. The use of RNAi-based screens to identify host proteins involved in viral replication. Future Microbiol. 2010;5(2):303-11. 
73. Puschnik AS, Majzoub K, Ooi YS, Carette JE. A CRISPR toolbox to study virushost interactions. Nat Rev Microbiol. 2017;15(6):351-64.

74. Furlong DB, Nibert ML, Fields BN. Sigma 1 protein of mammalian reoviruses extends from the surfaces of viral particles. J Virol. 1988;62(1):246-56.

75. Virgin HW, Bassel-Duby R, Fields BN, Tyler KL. Antibody protects against lethal infection with the neurally spreading reovirus type 3 (Dearing). J Virol. 1988;62(12):4594-604.

76. Smith RE, Zweerink HJ, Joklik WK. Polypeptide components of virions, top component and cores of reovirus type 3. Virology. 1969;39(4):791-810.

77. Fecek RJ, Busch R, Lin H, Pal K, Cunningham CA, Cuff CF. Production of Alexa Fluor 488-labeled reovirus and characterization of target cell binding, competence, and immunogenicity of labeled virions. J Immunol Methods. 2006;314(1-2):30-7.

78. Wetzel JD, Chappell JD, Fogo AB, Dermody TS. Efficiency of viral entry determines the capacity of murine erythroleukemia cells to support persistent infections by mammalian reoviruses. J Virol. 1997;71(1):299-306.

79. Chandran K, Walker SB, Chen Y, Contreras CM, Schiff LA, Baker TS, et al. In vitro recoating of reovirus cores with baculovirus-expressed outer-capsid proteins $\mu 1$ and $\sigma 3$. J Virol. 1999;73(5):3941-50.

80. Orchard RC, Wilen CB, Doench JG, Baldridge MT, McCune BT, Lee YC, et al. Discovery of a proteinaceous cellular receptor for a norovirus. Science. 2016;353(6302):933-6.

81. Doench JG, Fusi N, Sullender M, Hegde M, Vaimberg EW, Donovan KF, et al. Optimized sgRNA design to maximize activity and minimize off-target effects of CRISPR-Cas9. Nat Biotechnol. 2016;34(2):184-91.

82. Spence JS, Krause TB, Mittler E, Jangra RK, Chandran K. Direct visualization of ebola virus fusion triggering in the endocytic pathway. mBio. 2016;7(1):e01857-15.

83. Dehairs J, Talebi A, Cherifi Y, Swinnen JV. CRISP-ID: decoding CRISPR mediated indels by Sanger sequencing. Sci Rep. 2016;6:28973.

84. Olivio-Marin JC. Extraction of spots in biological images using multi-scale products. Pattern Recognition. 2002;35(9):1989-96. 
901

902

903

904

905

906

907

908

909

910

911

912

913

\section{FIGURE LEGENDS}

Fig. 1. CRISPR and siRNA screens identify NPC1 as a cellular factor required for reovirus infection. (A) The top 20 candidates from the CRISPR screen using reovirus strains T1L and T3D are ranked by their STAR scores. Heat map indicates STAR values. (B) Genes from the siRNA screen using reovirus strain T3SA+ common to the CRISPR screen using T1L and T3D, excluding ribosomal genes. Heat map indicates zscore values. (C) Venn diagram of genes from the CRISPR screens using T1L and T3D and the siRNA screen using T3SA+. (D) Molecular function pathways using Gene Ontology to analyze genes from the CRISPR screen common to T1L and T3D. (E) KEGG pathways identified for the CRISPR screen using T1L (red) and T3D (blue) and siRNA screen using T3SA+ (light blue).

\section{Fig. 2. Viral infectivity and titers following adsorption by reovirus virions and}

ISVPs. (A, B) WT, KO, and KO+ HBMECs were adsorbed with reovirus (A) virions or (B) ISVPs at MOIs of 10,000 or 100 particles/cell, respectively, and fixed at $18 \mathrm{~h}$ postadsorption. The percentage of infected cells was determined by enumerating reovirusinfected cells following immunostaining with a reovirus-specific antiserum. (C-F) WT, $\mathrm{KO}$, and $\mathrm{KO}+$ cells were adsorbed with reovirus $(\mathrm{C}, \mathrm{E})$ virions at an $\mathrm{MOI}$ of $1 \mathrm{PFU} / \mathrm{cell}$ or (D, F) ISVPs at an MOI of 5 particles/cell. Viral titers in cell-culture supernatants and lysates were determined by plaque assay at 0,24 , and $48 \mathrm{~h}$ post-adsorption. The results are presented as the mean of three independent experiments. Error bars indicated standard deviation. ${ }^{*}, P<0.05 ;{ }^{* *}, P<0.01$; ${ }^{* \star *}, P<0.001 ;{ }^{* \star * *}, P<0.0001$, as determined by t-test. 


\section{Fig. 3. Binding, internalization, and uncoating are not disrupted by cholesterol} accumulation in NPC1 KO HBMECs. (A) WT, KO, and KO+ HBMECs were adsorbed with Alexa 647 labeled-reovirus virions at an $\mathrm{MOI}$ of 10,000 particles $/$ cell at $4^{\circ} \mathrm{C}$ for $1 \mathrm{~h}$, fixed with $1 \%$ PFA, and analyzed for virus binding using flow cytometry. The results are presented as mean virus binding as determined by mean fluorescence intensity (MFI) of three independent experiments. Error bars indicated standard deviation. (B) WT, KO, and $\mathrm{KO}+\mathrm{HBMEC}$ were adsorbed with Alexa 647 labeled-reovirus virions at an $\mathrm{MOI}$ of 10,000 particles/cell at $4^{\circ} \mathrm{C}$ for $45 \mathrm{~min}$ and imaged using high magnification live-cell imaging, with images captured every $~ 25$ seconds. Representative micrographs from videos at the indicated intervals are shown. Scale bars, $10 \mu \mathrm{m}$. (C) WT, KO, and KO+ HBMECs were adsorbed with reovirus virions at an $\mathrm{MOI}$ of 10,000 particles/cell at $4^{\circ} \mathrm{C}$ for $1 \mathrm{~h}$ and lysed at the intervals post-adsorption shown. Cell lysates were subjected to electrophoresis and immunoblotting using a reovirus-specific polyclonal rabbit antiserum. The results are presented as the mean ratio of the $\delta$ and $\mu 1 \mathrm{C}$ bands from three independent experiments. Error bars indicate standard deviation. Differences are not significant, as determined by two-tailed unpaired t-test.

Fig. 4. Cytosolic entry of reovirus cores. (A) WT, KO, and KO+ HBMECs were adsorbed with Alexa 647 labeled-reovirus virions at an $\mathrm{MOI}$ of 10,000 particles/cell at $37^{\circ} \mathrm{C}$ for $45 \mathrm{~min}$ and fixed with $4 \% \mathrm{PFA}$ at $8 \mathrm{~h}$ post-adsorption. Cells were stained with DAPI, a CD-63-specific antibody to label endosomes, and an antiserum specific for reovirus cores, and imaged using confocal microscopy. Representative confocal micrographs are shown. (B) Colocalization of reovirus, cores, and endosomes was analyzed using the JaCoP plugin function from ImageJ. The results are presented as the mean colocalization (quantified by Manders coefficient) of $\sim 50$ cells from three 
951

independent experiments. Error bars indicate standard deviation. ${ }^{* \star}, P<0.01 ;{ }^{* \star}, P<$ 0.001 , as determined by two-tailed unpaired t-test.

Fig. 5. Synthesis of nascent RNA is reduced in NPC1 KO HBMECs. WT, KO, and $\mathrm{KO}+\mathrm{HBMECs}$ were adsorbed with reovirus virions at an $\mathrm{MOI}$ of $1 \mathrm{PFU} / \mathrm{cell}$ at $37^{\circ} \mathrm{C}$ for $1 \mathrm{~h}$, lysed at the intervals post-adsorption shown, and assayed for positive-sense reovirus s4 RNA by RT-qPCR. The results are presented as the mean number of copies of reovirus s4 RNA by qPCR from two independent experiments. Error bars indicate standard errors of the mean. ${ }^{* *}, P<0.01 ;{ }^{* * *}, P<0.001$, as determined by $\mathrm{t}-$ test.

Fig. 6. HßCD treatment restores reovirus infection of NPC1 KO HBMECs. WT, KO, and $\mathrm{KO}+\mathrm{HBMECs}$ were pretreated with $1 \mathrm{mM} \mathrm{H \beta CD}$ or PBS for $24 \mathrm{~h}$, adsorbed with reovirus virions or ISVPs at MOls of 10,000 or 100 particles/cell, respectively, and fixed at $18 \mathrm{~h}$ post-adsorption. The percentage of infected cells was determined by enumerating reovirus-infected cells following immunostaining with a reovirus-specific antiserum. The results are presented as the mean of three independent experiments. Error bars indicated standard deviation. ${ }^{* \star *}, P<0.001$ as determined by two-tailed unpaired t-test.

\section{SUPPLEMENTAL MATERIALS}

FIGURES AND MOVIES

\section{Fig. S1. Effect on cholesterol distribution by disruption of NPC1 expression. (A,} B) Lysates of WT, KO, and KO+ HBMECs were subjected to electrophoresis and 
immunoblotting using an NPC1 antiserum. GAPDH was used as loading control. A representative immunoblot is shown. The results are presented as the mean of two independent experiments. Error bars indicate standard deviation. Statistical analysis was done by two-tailed unpaired t-test. (C) WT, KO, and KO+ HBMECs were stained with filipin III to detect cholesterol distribution. Representative images are shown. Scale bars, $10 \mu \mathrm{m}$. (D) WT, KO, and KO+ HBMECs were stained with filipin III and an antiCD63 antibody to detect the subcellular localization of cholesterol. Representative images are shown. Scale bars, $10 \mu \mathrm{m}$.

Fig. S2. Viral infectivity following adsorption by T1L, T3D, and T3SA+ virions. (A, B) WT, KO, and KO+ HBMECs were adsorbed with reovirus virions at MOls of 10,000 particles/cell, and fixed at $18 \mathrm{~h}$ post-adsorption. The percentage of infected cells was determined by enumerating reovirus-infected cells following immunostaining with a reovirus-specific antiserum. Error bars indicated standard deviation. ${ }^{* *}, P<0.01 ;{ }^{* \star *}, P$ $<0.001$, as determine by 2-way ANOVA, Tukey's multiple comparisons test.

Fig. S3. $H \beta C D$ treatment restores cholesterol efflux in $K O$ cells. (A) WT, $K O$, and $\mathrm{KO}+\mathrm{HBMEC}$ s were treated with $\mathrm{H} \beta C D$ at the concentrations shown for $48 \mathrm{~h}$ and assessed for viability using the Presto blue cell viability reagent. The results are presented as the mean cell viability of three independent experiments. Error bars indicated standard deviation. ${ }^{* *}, P<0.01 ;{ }^{* * *}, P<0.001 ;{ }^{* * *}, P<0.0001$, as determined by two-way ANOVA. (B, C) Cells were treated with $1 \mathrm{mM} \mathrm{H} \beta C D$ or PBS (mock) for $48 \mathrm{~h}$, fixed with 4\% PFA, stained with filipin III, and imaged using confocal microscopy. (B) The results are presented as the mean filipin III staining (quantified by $\mathrm{MFI}$ ) of $\sim 50$ cells from three independent experiments. Error bars indicate the minimum 
1001

1002

1003

1004

1005

1006

1007

1008

1009

1010

1011

1012

1013

1014

1015

1016

1017

1018

and the maximum values. ${ }^{*}, P<0.05 ;{ }^{* * *}, P<0.0001$, as determined by two-tailed unpaired t-test. (C) Representative images of cholesterol distribution in H $\beta C D$-treated and mock-treated cells are shown. Scale bars, $10 \mu \mathrm{m}$.

VIDEO 1, 2, and 3. High-magnification, live-cell microscopy of fluorescent reovirus virion transport in WT, KO, and KO+ HBMECs. (1) WT, (2) KO, and (3) $\mathrm{KO}+$ cells were adsorbed with Alexa 647-labeled reovirus virions at an $\mathrm{MOI}$ of 10,000 particles/cell at $4^{\circ} \mathrm{C}$ for $45 \mathrm{~min}$. Fluorescence and brightfield images were captured every $~ 25$ seconds for $36 \mathrm{~min}$.

\section{VIDEO 4, 5, and 6. Tracking of fluorescent reovirus virions recruited to a}

perinuclear region following entry. Trajectories of reovirus virions during

internalization into WT, KO, and KO+ HBMECs from videos 1, 2, and 3 were tracked with the spot-tracking plugin function of Icy-Bioimage analysis software (84). Cell contour was defined as a region of interest $(\mathrm{ROI})$, and $\sim 7$ pixels/spot were monitored. The colored bar represents the trajectory depending on time, in which each color (from yellow to red) corresponds to an interval of $\sim 7.5 \mathrm{~min}$ in the time-lapse videos. Scale bars, $10 \mu \mathrm{m}$. 

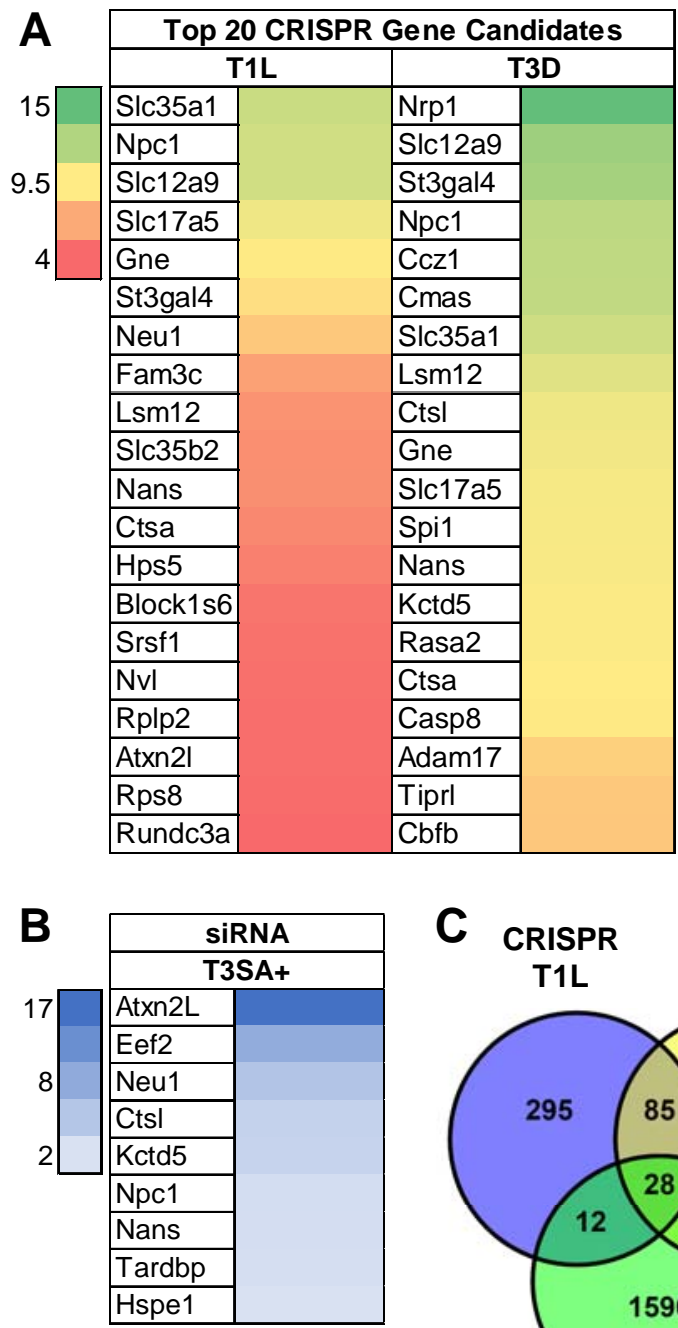

D

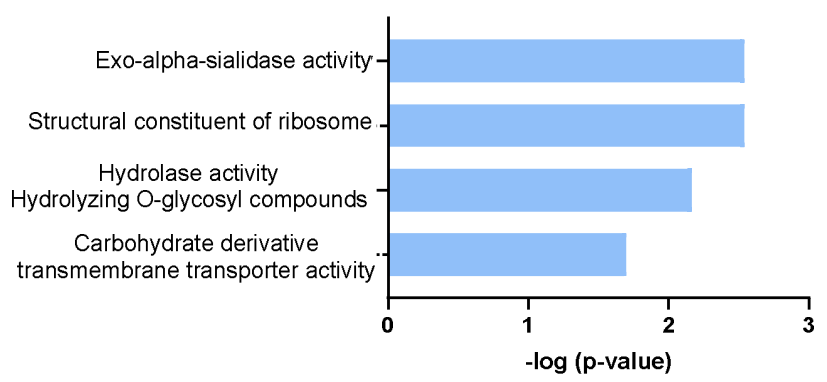

$\mathbf{E}$
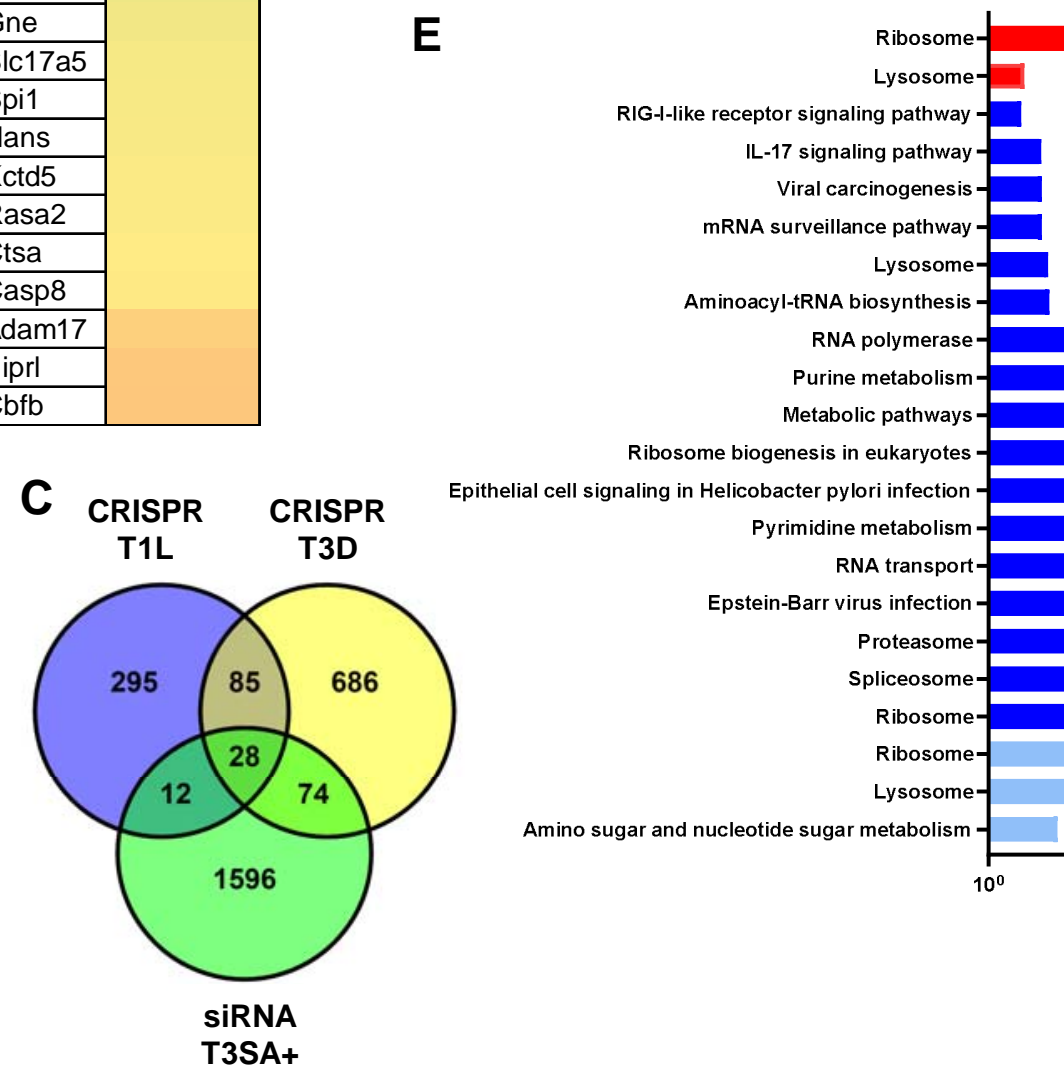

Amino sugar and nucleotide sugar metabolism

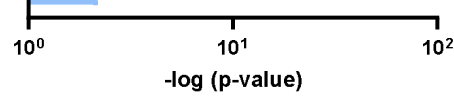

FIG 1 CRISPR and siRNA screens identify NPC1 as a cellular factor required for reovirus infection. (A) The top 20 candidates from the CRISPR screen using reovirus strains T1L and T3D are ranked by their STAR scores. Heat map indicates STAR values. (B) Genes from the siRNA screen using reovirus strain T3SA+ common to the CRISPR screen using T1L and T3D, excluding ribosomal genes. Heat map indicates z-score values. (C) Venn diagram of genes from the CRISPR screens using T1L and T3D and the siRNA screen using T3SA+. (D) Molecular function pathways using Gene Ontology to analyze genes from the CRISPR screen common to T1L and T3D. (E) KEGG pathways identified for the CRISPR screen using T1L (red) and T3D (blue) and siRNA screen using T3SA+ (light blue). 

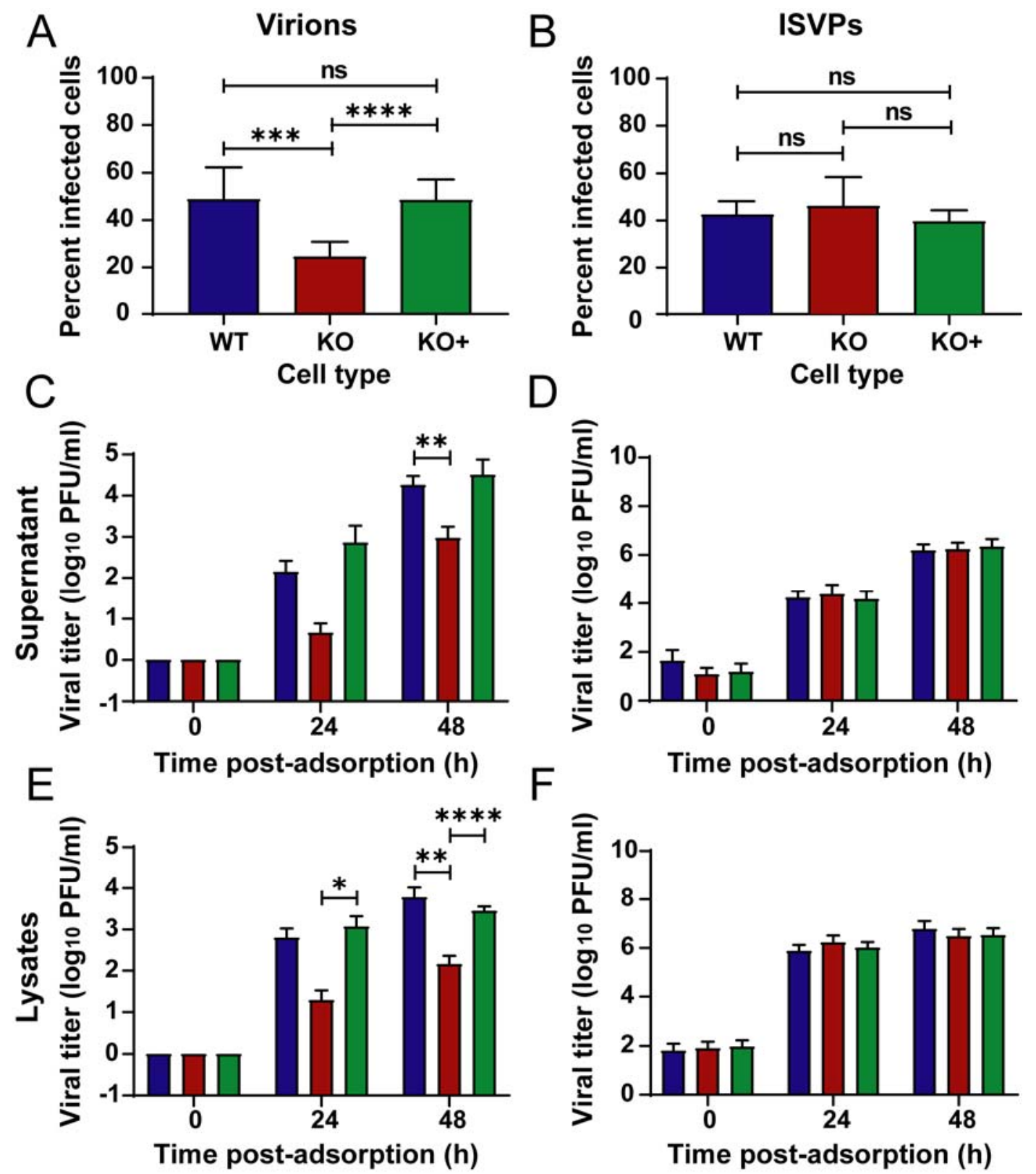

$\mathrm{F}$

Time post-adsorption (h)

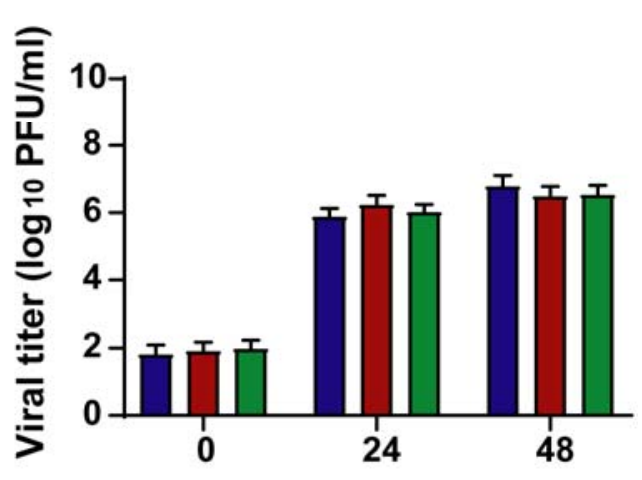

Time post-adsorption (h)

FIG 2 Viral infectivity and titers following adsorption by reovirus virions and ISVPs. $(A, B) W T, K O$, and $K O+H B M E C s$ were adsorbed with reovirus $(A)$ virions or $(B)$ ISVPs at MOls of 10,000 or 100 particles/cell, respectively, and fixed at $18 \mathrm{~h}$ postadsorption. The percentage of infected cells was determined by enumerating reovirus-infected cells following immunostaining with a reovirus-specific antiserum. (C-F) WT, KO, and $\mathrm{KO}+$ cells were adsorbed with reovirus $(\mathrm{C}, \mathrm{E})$ virions at an $\mathrm{MOI}$ of $1 \mathrm{PFU} / \mathrm{cell}$ or (D, F) ISVPs at an MOI of 5 particles/cell. Viral titers in cell-culture supernatants and lysates were determined by plaque assay at 0,24 , and $48 \mathrm{~h}$ postadsorption. The results are presented as the mean of three independent experiments. Error bars indicated standard deviation. ${ }^{*}, P<0.05 ;{ }^{* *}, P<0.01$; ${ }^{* * *}, P$ $<0.001 ;{ }^{* \star \star *}, P<0.0001$, as determined by t-test. 
A

B
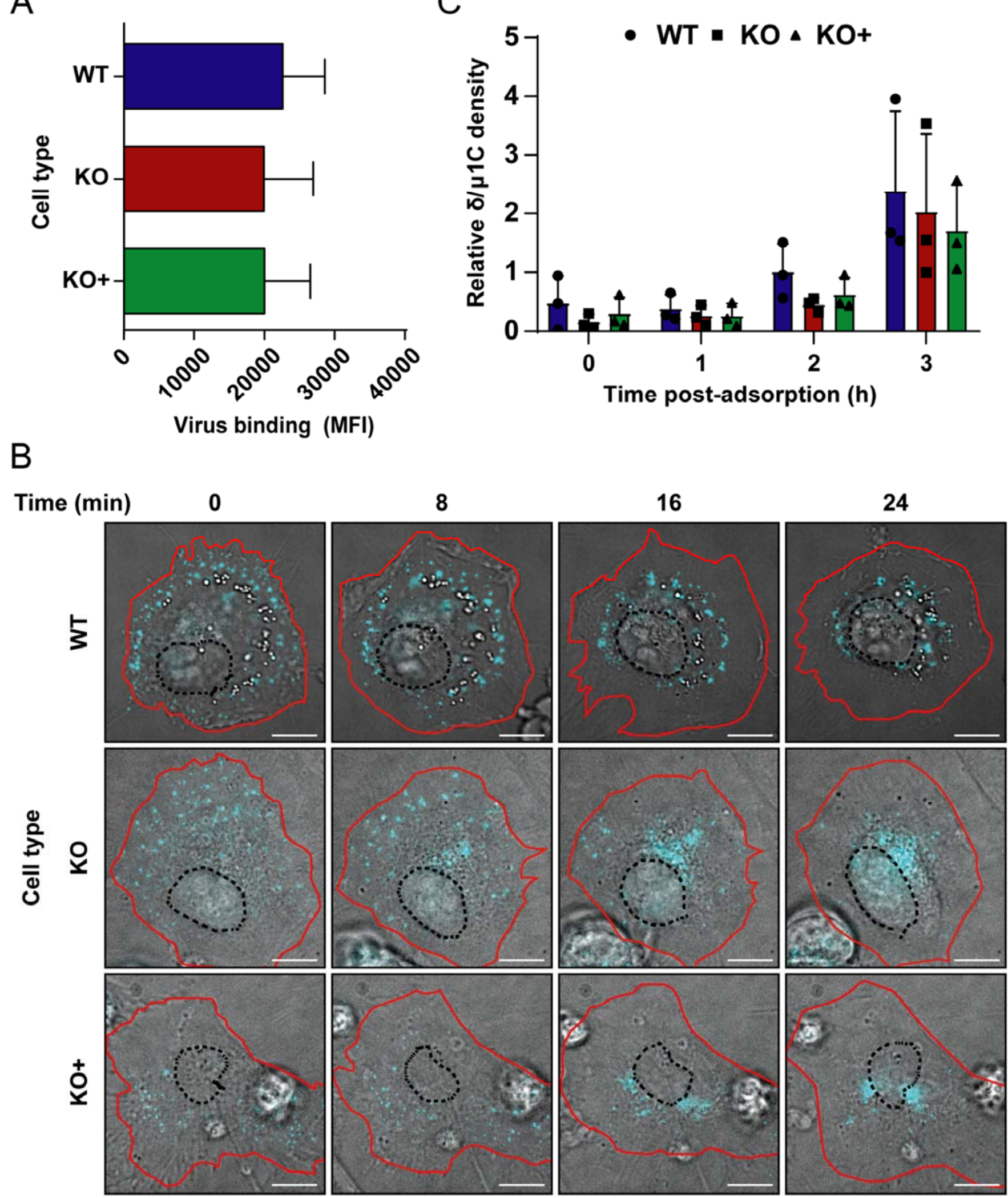

Virus binding (MFI)

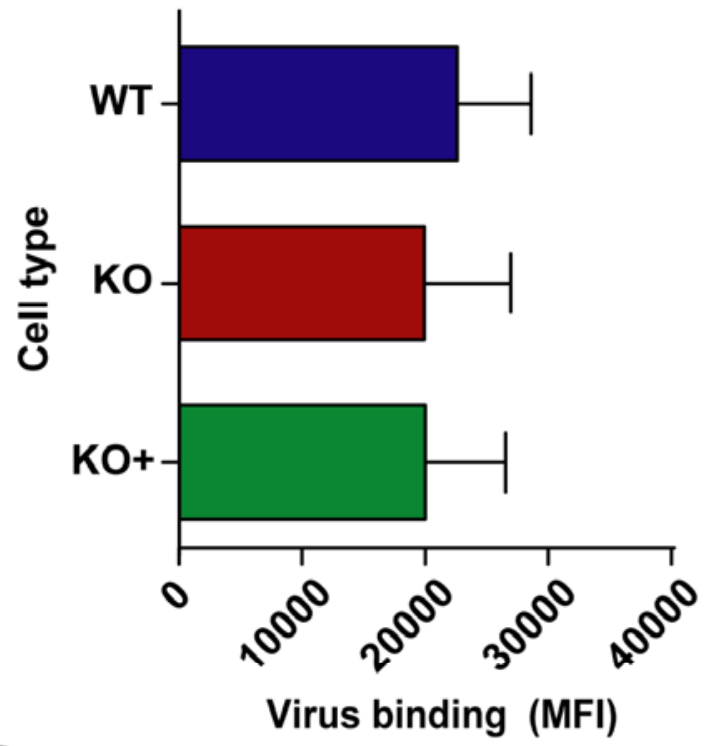

FIG 3 Binding, internalization, and uncoating are not disrupted by cholesterol accumulation in NPC1 KO HBMECs. (A) WT, KO, and KO+ HBMECs were adsorbed with Alexa 647 labeled-reovirus virions at an MOI of 10,000 particles/cell at $4{ }^{\circ} \mathrm{C}$ for $1 \mathrm{~h}$, fixed with $1 \%$ PFA, and analyzed for virus binding using flow cytometry. The results are presented as mean virus binding as determined by mean fluorescence intensity (MFI) of three independent experiments. Error bars indicated standard deviation. (B) WT, KO, and KO+ HBMECs were adsorbed with Alexa 647 labeled-reovirus virions at an MOI of 10,000 particles/cell at $4^{\circ} \mathrm{C}$ for 45 min and imaged using high magnification live-cell imaging, with images captured every $\sim 25$ seconds. Representative micrographs from videos at the indicated intervals are shown. Scale bars, $10 \mu \mathrm{m}$. (C) WT, KO, and KO+ HBMECs were adsorbed with reovirus virions at an $\mathrm{MOI}$ of 10,000 particles/cell at $4^{\circ} \mathrm{C}$ for $1 \mathrm{~h}$ and lysed at the intervals post-adsorption shown. Cell lysates were subjected to electrophoresis and immunoblotting using a reovirus-specific polyclonal rabbit antiserum. The results are presented as the mean ratio of the $\delta$ and $\mu 1 \mathrm{C}$ bands from three independent experiments. Error bars indicate standard deviation. Differences are not sianificant. as determined bv two-tailed unbaired t-test. 
A
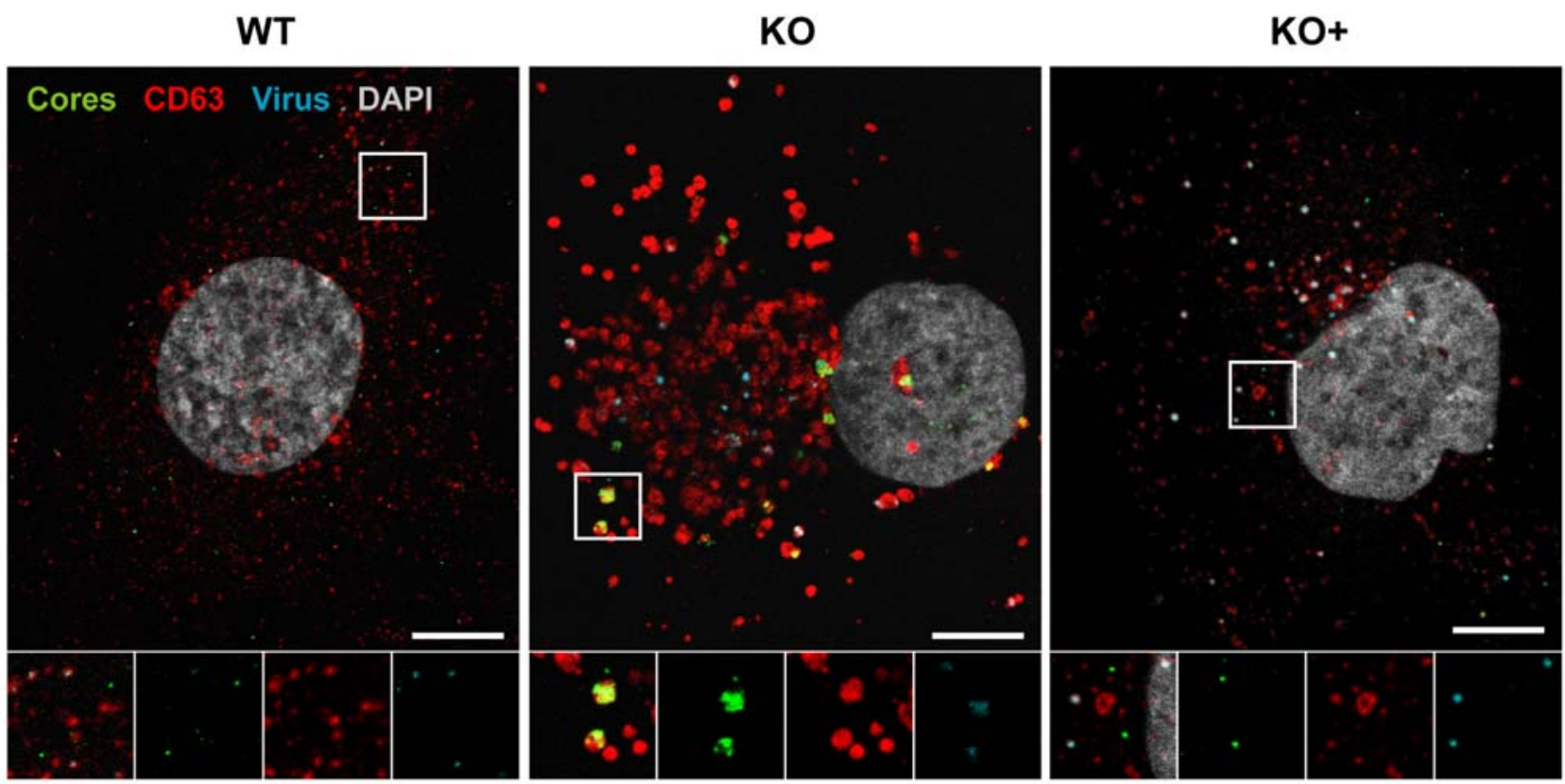

B
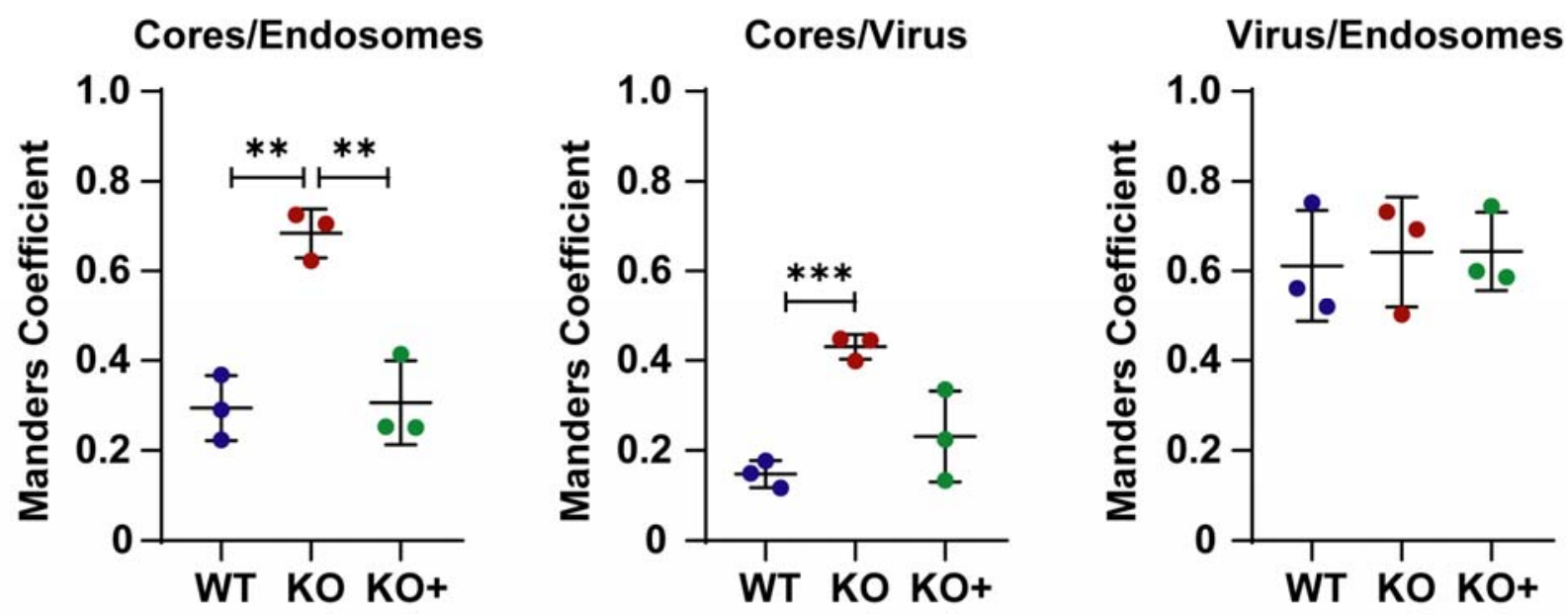

FIG 4 Cytosolic entry of reovirus cores. (A) WT, KO, and KO+ HBMECs were adsorbed with Alexa 647 labeled-reovirus virions at an $\mathrm{MOI}$ of 10,000 particles/cell at $37^{\circ} \mathrm{C}$ for $45 \mathrm{~min}$ and fixed with $4 \%$ PFA at $8 \mathrm{~h}$ post-adsorption. Cells were stained with DAPI, a CD-63-specific antibody to label endosomes, and an antiserum specific for reovirus cores, and imaged using confocal microscopy. Representative confocal micrographs are shown. (B) Colocalization of reovirus, cores, and endosomes was analyzed using the JaCoP plugin function from ImageJ. The results are presented as the mean colocalization (quantified by Manders coefficient) of $\sim 50$ cells from three independent experiments. Error bars indicate standard deviation. ${ }^{* *}, P<0.01 ;{ }^{* * *}, P$ $<0.001$, as determined by two-tailed unpaired t-test. 


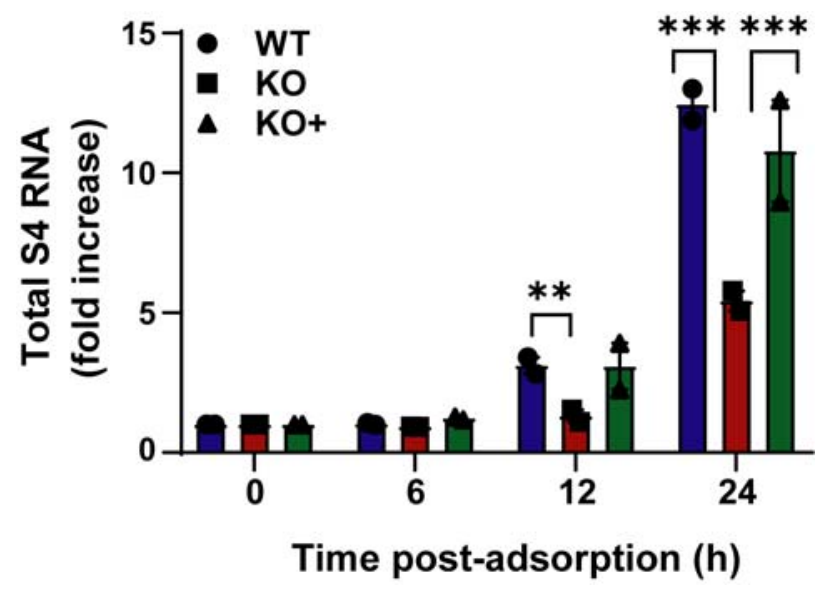

FIG 5 Synthesis of nascent RNA is reduced in NPC1 KO HBMECs. WT, KO, and $\mathrm{KO}+\mathrm{HBMEC}$ were adsorbed with reovirus virions at an $\mathrm{MOI}$ of $1 \mathrm{PFU} / \mathrm{cell}$ at $37^{\circ} \mathrm{C}$ for $1 \mathrm{~h}$, lysed at the intervals post-adsorption shown, and assayed for positive-sense reovirus s4 RNA by RT-qPCR. The results are presented as the mean number of copies of reovirus 54 RNA by qPCR from two independent experiments. Error bars indicate standard errors of the mean. ${ }^{* *}, P<0.01{ }^{* * *}, P<0.001$, as determined by $\mathrm{t}-$ test. 
- Untreated $\square \mathrm{HBCD}$
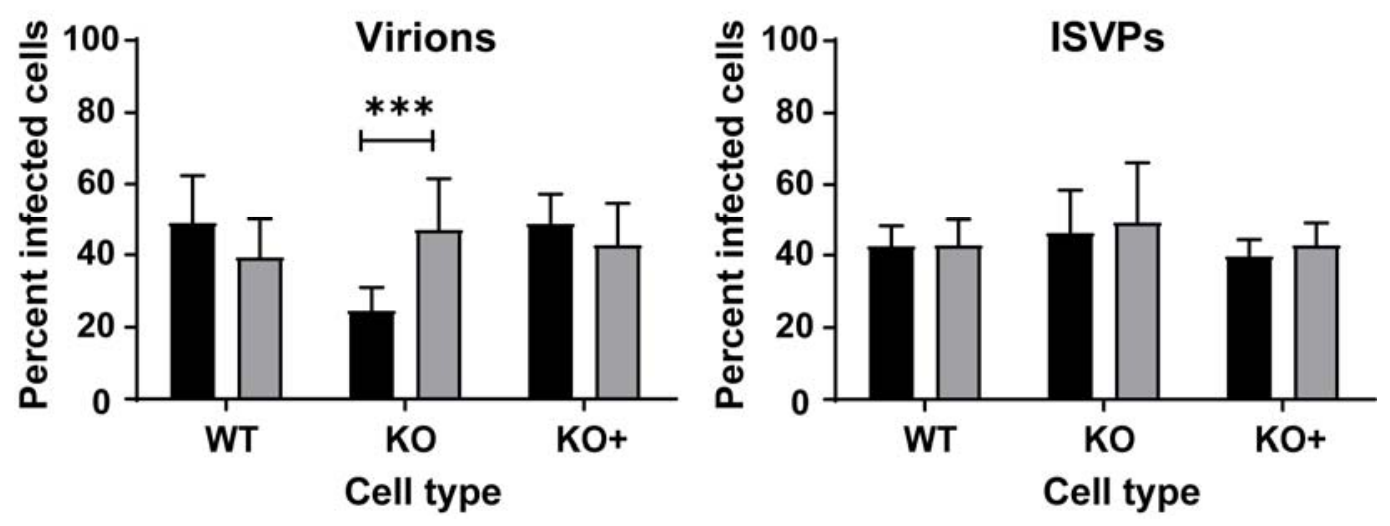

FIG $6 \mathrm{H} \beta C D$ treatment restores reovirus infection of NPC1 KO HBMECs. WT, KO, and $\mathrm{KO}+\mathrm{HBMEC}$ were pretreated with $1 \mathrm{mM} \mathrm{H \beta CD}$ or PBS for $24 \mathrm{~h}$, adsorbed with reovirus virions or ISVPs at MOls of 10,000 or 100 particles/cell, respectively, and fixed at $18 \mathrm{~h}$ post-adsorption. The percentage of infected cells was determined by enumerating reovirus-infected cells following immunostaining with a reovirus-specific antiserum. The results are presented as the mean of three independent experiments. Error bars indicated standard deviation. ${ }^{* * *}, P<0.001$ as determined by two-tailed unpaired t-test. 